Journal of Finance and Investment Analysis, vol.8, no.2, 2019, 69-110

ISSN: 2241-0988 (print version), 2241-0996 (online)

Scienpress Ltd, 2019

\title{
Anatomy of Chinese Futures Markets
}

\author{
Ahmet Gönc ̈̈ ${ }^{12}$ and Yurun Yang ${ }^{3}$
}

\begin{abstract}
In this study, the fundamental empirical characteristics of the Chinese futures markets, which includes all the liquid financial and commodity futures traded in mainland China, are analyzed at different time scales. The comprehensive results for the whole range of products provide valuable insight for the market practitioners, academics, and regulators. Stylized facts from the stock markets such as serial correlation, volatility clustering, non-normality, gain/loss asymmetry, risk characteristics and structural dependences are characterized. Futures returns in the Chinese futures markets show certain similarities and also differences from the stock markets in terms of the stylized facts.
\end{abstract}

\section{Mathematics Subject Classification: G10; G15}

Keywords: Futures markets; commodity futures; high-frequency returns; stylized facts

\footnotetext{
${ }^{1}$ Research Institute of Quantitative Finance, Xi'an Jiaotong-Liverpool University, Suzhou, China. E-mail: Ahmet.Goncu@xjtlu.edu.cn

2 China Hedge Fund Research Center, Shanghai Advanded Institute of Finance (SAIF), Shanghai Jiaotong University, China.

3 Department of Mathematical Sciences, Xi'an Jiaotong Liverpool University, China.
} 


\section{Introduction}

Chinese futures markets offer investors a wide range of futures contracts on commodities, treasury bonds, and stock market indices. As of today, there are fifty-one futures products in the Chinese futures markets which includes the Shanghai Futures Exchange (SHFE), Dalian Commodity Exchange (DCE), Zhengzhou Commodity Futures Exchange (ZCE) and the China Financial Futures Exchange (CFFEX). However, excluding the very recently introduced contracts and the relatively illiquid contracts, there are 37 contracts remaining with sufficiently long historical time series, i.e. with longer than two years of history. The financial futures include three types of stock market index futures, whereas the bond futures consists of the 5-year and 10-year Chinese treasury bonds as the underlying. For a large number of commodity futures such as copper, iron ore, soybean, soybean oil and so on, the Chinese market is the largest globally in terms of trading volume ${ }^{4}$. The history of the Chinese futures markets dates back to the 1990s when the first commodity market was established in Zhengzhou for the trade of grains. The Chinese futures markets can be described as highly liquid (at least for many products) and speculative market. Relatively, different from the stock markets, where around $80 \%$ of the account holders are retail investors, futures markets in China are mainly dominated by the hedge funds, CTAs, and futures companies ${ }^{5}$.

The stock market turmoil that started on June 12nd, 2015 led to the introduction of new restrictions on the trading of the index futures in China. New regulations allow each account to hold a maximum of ten index futures contracts at most. Shanghai composite index lost one-third of its value within one month of the turmoil. Furthermore, since stock index futures are considered to accelerate the fall in the Chinese stock markets, which is heavily retail in character, margin requirements for index futures are raised to much higher levels compared to other futures products in China. Therefore, index

\footnotetext{
${ }^{4}$ See 2015 WFE/IOMA Derivatives Market Survey reported by World Federation of Exchanges (WFE) and IOMA, "the commodity options and futures traded in Shanghai and Dalian accounting for $50 \%$ of the volume traded in 2015 in terms of number of contracts" (published, April 2nd, 2015).

${ }^{5}$ More than two thousand CTA funds are reporting their weekly returns in the database of the China Hedge Fund Research Center at the Shanghai Advanced Institute of Finance (SAIF).
} 
futures have a clearly different structural relationship with the stock markets, especially when compared to commodity futures. The findings of this study show that index futures stand alone in terms of their statistical properties in comparison to commodity futures. In this study, we also document the dependence and correlation between these markets at different time scales using the principle components analysis. Therefore, depending on the investment horizon or trading strategy diversification benefits differ across sectors of futures products.

Understanding the dynamics of a market and investor behavior is crucial when exploring stylized facts of a financial market. Our goal is to provide financial modelers, whether in academics or industry, the main empirical characteristics of futures returns and its implications for investment and risk management. The literature on the Chinese futures markets is not sufficient enough to understand the general characteristics of this market and this study aims to fill this gap in the academic literature.

The stylized facts in the stock returns' is extensively studied and a survey of these facts and the techniques utilized in the identification of these features can be found in [31] and [11]. Some of the well-known stylized facts of stock returns are: fat tails and leptokurtic distribution of returns, existence of co-integration, volatility clustering, leverage effect, long memory, volume and volatility correlation, etc. [13] characterizes the dependence between the commodity and stock markets via copulas fitted to the data, whereas the leverage effect and downside correlations are documented in [7].

Although the literature on stylized facts of stock returns is extensive, there have been only a few studies focusing on the Chinese futures markets. Furthermore, none of these studies consider focusing on the comprehensive futures markets with the goal of analyzing its fundamental characteristics or empirical properties. Volatility behavior in the Chinese futures markets is studied in [8]. In this study, only four commodity futures are analyzed and it is shown that returns have asymmetric effects on volatility, in particular, negative returns have a greater effect on the volatility than positive returns do. Volume is documented to be positively related to volatility, whereas open interest is negatively related to volatility, and the extent of large-volume traders participation is also positively related to volatility. In another study focusing on the Chinese futures market, [21] analyses the relationship between the Chinese and 
international futures prices of copper, aluminum, soybean, and wheat, using Johansens cointegration test, error correction model, the Granger causality test and impulse response analyses. One of the shortcomings of the existing studies on the Chinese futures markets is the use of few contracts and low frequency returns.

In this study, both high and low-frequency futures returns are analyzed for the whole set of futures products traded in China with the aim of documenting major empirical characteristics across different products. Second, futures returns are analyzed with a battery of statistical tests for serial correlation, volatility clustering, co-integration, leverage effects, and so on. Finally, by considering the principle components analysis for the high-frequency and low-frequency futures returns, we are able to characterize the dependence structures across the whole market and across different industries. This analysis is in particular useful for understanding potential factors that drive the dependence between different futures products in China. To the best of our knowledge, this article addresses a variety of fundamental properties of the Chinese futures markets for the first time in the literature.

\section{Data}

Working with a futures price database is a delicate issue compared with the stock prices. The obvious reason for this difficulty is the co-existence of different maturity contracts being traded at the same time with different trading volumes. The fundamental economic intuition tells us that the most actively traded contract reflects the futures price best in comparison to the contracts with lower trading activity. Although, the economic intuition is straightforward, in the academic literature the construction of a futures prices dataset is done in alternative ways.

Empirical analysis of stylized facts should be based on a dataset that can reflect the actual trading in the market. In our data construction method, the price of each commodity or financial futures comes from the most active contract of each trading day. As a natural consequence, the dates for the most active contracts changes (roll-over dates) are not uniform across different products. Furthermore, even the number of roll-overs (i.e. switch dates between 
maturities) is not the same over years. The number of roll-overs per annum is different across different contracts, and thus uniform methods applied in the literature are indeed not very suitable. For example, the most active contract for futures traded in August can be the January contract, while it might be the October contract for another futures contract. Therefore, we do not impose any rules on the roll-over dates as it is common in the literature, but simply take the market's choice of the front-contract for each product. This approach is in line with the practice of the hedge funds or commodity trading advisors (CTAs) operating in the Chinese futures markets.

Our dataset covers the recent period between 2015-05-22 and 2017-08-09 at the daily and minute level prices, which have 543 trading days of observations for all of the 37 futures products that are highly liquid. In Figure 1 the normalized prices (i.e. starting with one) of all the futures contracts utilized in this study are plotted for the sample of 543 trading days. The products are grouped with respect to their industries and from this figure, one can conjecture that there is a high degree of dependence within the products of the same industry.

The dataset processing technique utilized in this paper offers a significant advantage over the current literature. Previous studies compile the data series by the "immediate roll" Miffre and Rallis (2007), Shen et al. (2007) or the "gradual roll" Wang and Yu (2004), Marshall et al. (2008) approaches. However, all these roll-over methodologies are based on the strong assumption of liquidity and implement the roll-over near the expiration date in the same way across all products. Therefore, a potential problem arises, the contracts traded actively in the market are not necessarily those that are used in the empirical analysis. To avoid this drawback, the trading volume and open interest are observed at the beginning of every trading day, and the most actively traded contracts are utilized in the empirical analysis.

Due to the roll-over issue, the daily log-returns are calculated from the close to close prices when there is no roll-over between contracts, whereas if there is a roll-over to another maturity, then the return is obtained from the open to close price for the roll-over date. The intuition behind this approach is that long or short positions are closed from the old contract at the end of the day and a new position is opened from the next open with the new active contract. Furthermore, since most traders and CTAs prefer daily or few days trading 

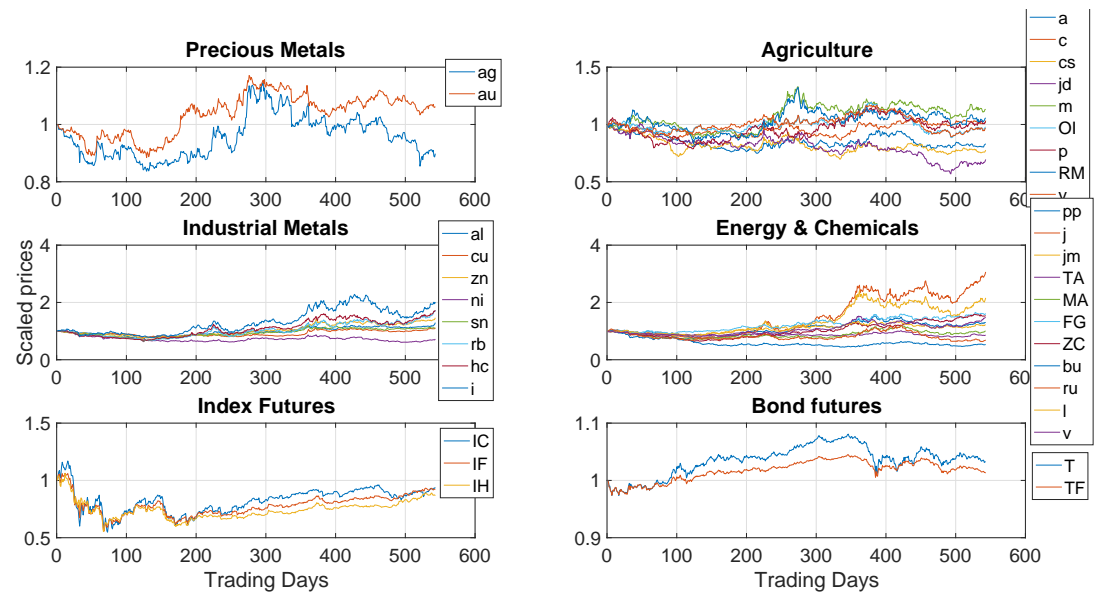

Figure 1: Plot of the scaled futures prices (initial price set as 1) for the thirty seven actively traded futures contracts in China for the period from 2015-05-22 to 2017-08-09 containing 543 trading days.

horizons in the futures markets, the movement between the old and new active contracts often occure rapidly. Most of the market participants, in particular short term speculative traders, move from old to the new active contracts within few days time and we observe the sudden change in the liquidity between the old and new active contracts. This explains why the financial industry does not consider the fixed roll-over rules as it is utilized in the academic studies.

Typically, there are three to five days per year at which the roll-over between different maturity contracts occurs for each commodity and the number of the roll-over dates between active contracts are not uniform across different products. Furthermore, the illiquid commodity futures ${ }^{6}$ with less than 200 trades on its main contract per day are filtered-out. ${ }^{7}$ For the high-frequency log-returns of the futures, we calculate the log-returns using the close prices at the 1,5, 15, and 30-minute intervals during the trading hours of each futures contract.

At the minute level frequency, due to the differences in the trading hours across different futures, the number of observations per day range from 225 to 555. For example, for the futures with the overnight trading hours, our sample

\footnotetext{
${ }^{6}$ The threshold for filtering is not often exceeded except one or two commodities out of thirty-one.

${ }^{7}$ The inclusion of illiquid contracts would create a distortion in the empirical results since low liquidity contracts would have fewer implications for traders as well.
} 
size for the one minute level prices is 298,590 .

In Table 1 we present the commodity futures contracts in the Chinese market with the details such as the exchange tickers, commission fees, trading hours, launch dates of products, and the maturity dates of contracts. We consider the dataset ${ }^{8}$ where all the 32 different commodities and 5 financial futures that co-exist simultaneously during the sample period.

In Table 2 descriptive statistics for all the futures products considered in this study are presented. For brevity normality test results are not presented, however, it can be noted that normality is rejected for all the contracts at the $95 \%$ confidence level based on the Jarque-Bera and Anderson-Darling test statistics. Table 2 shows that all the daily log-returns exhibit high kurtosis and fat tails, whereas the skewness is not always negative as commonly observed in the stock returns. By repeating the calculation of descriptive statistics at different sub-samples we observe that the skewness in futures returns is as likely to be positive as it can be negative depending on the trend in prices for each sub-period. For space consideratinos the descriptive statistics for subperiods are not presented, however, we can simply state that the negative skewness is not a characteristic of futures returns in China. Two fundamental differences between the stock markets and futures markets in China might have a significant effect on the extent of kurtosis, value-at-risk, and expected shortfall values.

First, in the futures markets, the price limits are set as 5\%, whereas in the stock markets these limits are set as $10 \%$. Second, short sales are not allowed in the equity markets in China, whereas in the futures markets taking a short position is as easy as taking a long position. Third, high leverage exists only in the futures markets in China enabling greater flexibility to increase position sizes in the long or short side quickly. Last but not least, contrary to the stock markets, commodity futures do not show strong dependence with respect to a single market factor. In futures markets, we observe strong dependence with respect to the industry and sectors of futures products. The issue of finding factors to decompose the futures returns is treated more extensively in this study using the principle component analysis. Finally, it is important to note that the Value-at-Risk (VaR) and expected shortfall values for the long

\footnotetext{
${ }^{8}$ The data is obtained from JYB-Capital, which is a Chinese hedge fund focusing on quantitative trading.
} 
Table 1: Market information for commodity futures contracts with high trading volume.

\begin{tabular}{|c|c|c|c|c|c|c|c|c|c|}
\hline Commodity & Symbol & Exchange & Contract unit & Tick size & Commission Fee & Maturity months & Night trading & Last trading day & Start date \\
\hline Copper & $\mathrm{CU}$ & SHFE & $5 \mathrm{~T} / \mathrm{H}$ & 10RMB/T & $0.5 \% \%$ & FGHJKMNQUVXZ & 21:00-01:00 & 15th trading day & $1993-03-01$ \\
\hline Aluminium & $\mathrm{AL}$ & SHFE & $5 \mathrm{~T} / \mathrm{H}$ & $5 \mathrm{RMB} / \mathrm{T}$ & 3RMB & FGHJKMNQUVXZ & 21:00-01:00 & 15th trading day & $1992-05-28$ \\
\hline Zinc & $\mathrm{ZN}$ & SHFE & $5 \mathrm{~T} / \mathrm{H}$ & $5 \mathrm{RMB} / \mathrm{T}$ & $3 \mathrm{RMB}$ & FGHJKMNQUVXZ & 21:00-01:00 & 15th trading day & $2007-03-26$ \\
\hline Nickel & NI & SHFE & $1 \mathrm{~T} / \mathrm{H}$ & 10RMB/T & $6 \mathrm{RMB}$ & FGHJKMNQUVXZ & 21:00-01:00 & 15th trading day & $2015-03-27$ \\
\hline Tin & SN & SHFE & $1 \mathrm{~T} / \mathrm{H}$ & $10 \mathrm{RMB} / \mathrm{T}$ & $3 \mathrm{RMB}$ & FGHJKMNQUVXZ & 21:00-01:00 & 15th trading day & $2015-03-27$ \\
\hline Gold & $\mathrm{AU}$ & SHFE & $1 \mathrm{KG} / \mathrm{H}$ & $0.05 \mathrm{RMB} / \mathrm{G}$ & 10RMB & FGHJKMNQUVXZ & $21: 00-02: 30$ & 15th trading day & 2008-01-09 \\
\hline Silver & $\mathrm{AG}$ & SHFE & $15 \mathrm{KG} / \mathrm{H}$ & $1 \mathrm{RMB} / \mathrm{KG}$ & $0.5 \% \%$ & FGHJKMNQUVXZ & 21:00-02:30 & 15th trading day & $2012-05-10$ \\
\hline Screw Steel & $\mathrm{RB}$ & SHFE & $10 \mathrm{~T} / \mathrm{H}$ & $1 \mathrm{RMB} / \mathrm{T}$ & $1 \% \%$ & FGHJKMNQUVXZ & 21:00-23:00 & 15th trading day & $2009-03-27$ \\
\hline Hot Rolled Coil & $\mathrm{HC}$ & SHFE & $10 \mathrm{~T} / \mathrm{H}$ & $1 \mathrm{RMB} / \mathrm{T}$ & $1 \% \%$ & FGHJKMNQUVXZ & 21:00-23:00 & 15th trading day & 2014-03-21 \\
\hline Petroleum Asphalt & $\mathrm{BU}$ & SHFE & $10 \mathrm{~T} / \mathrm{H}$ & $2 \mathrm{RMB} / \mathrm{T}$ & $1 \% \%$ & FGHJKMNQUVXZ & 21:00-23:00 & 15th trading day & 2013-10-09 \\
\hline Rubber & $\mathrm{RU}$ & SHFE & $10 \mathrm{~T} / \mathrm{H}$ & $5 \mathrm{RMB} / \mathrm{T}$ & $0.45 \% \%$ & FHJKMNQUVX & 21:00-23:00 & 15th trading day & $1993-11-01$ \\
\hline Corn & C & $\mathrm{DCE}$ & $10 \mathrm{~T} / \mathrm{H}$ & $1 \mathrm{RMB} / \mathrm{T}$ & 1.2RMB & FHKNUX & N/A & 10th trading day & $2004-09-22$ \\
\hline Corn Starch & CS & DCE & $10 \mathrm{~T} / \mathrm{H}$ & $1 \mathrm{RMB} / \mathrm{T}$ & $1.5 \mathrm{RMB}$ & FHKNUX & $\mathrm{N} / \mathrm{A}$ & 10th trading day & 2004-12-19 \\
\hline Soybean 1 & A & DCE & $10 \mathrm{~T} / \mathrm{H}$ & $1 \mathrm{RMB} / \mathrm{T}$ & 2RMB & FHKNUX & 21:00-23:30 & 10th trading day & $2002-03-15$ \\
\hline Soybean Meal & M & DCE & $10 \mathrm{~T} / \mathrm{H}$ & $1 \mathrm{RMB} / \mathrm{T}$ & 1.5RMB & FHKNQUXZ & 21:00-23:30 & 10th trading day & $2000-07-17$ \\
\hline Soybean Oil & $\mathrm{Y}$ & DCE & $10 \mathrm{~T} / \mathrm{H}$ & $2 \mathrm{RMB} / \mathrm{T}$ & $2.5 \mathrm{RMB}$ & FHKNQUXZ & 21:00-23:30 & 10th trading day & 2006-01-09 \\
\hline Palm Oil & $\mathrm{P}$ & DCE & $10 \mathrm{~T} / \mathrm{H}$ & $2 \mathrm{RMB} / \mathrm{T}$ & $2.5 \mathrm{RMB}$ & FGHJKMNQUVXZ & 21:00-23:30 & 10th trading day & $2007-10-29$ \\
\hline Egg & $\mathrm{JD}$ & DCE & $5 \mathrm{~T} / \mathrm{H}$ & $1 \mathrm{RMB} / 500 \mathrm{KG}$ & 1.5RMB & FGHJKMUVXZ & N/A & 10th trading day & 2013-11-08 \\
\hline Polythene & $\mathrm{L}$ & DCE & $5 \mathrm{~T} / \mathrm{H}$ & 5RMB/T & 2RMB & FGHJKMNQUVXZ & N/A & 10th trading day & $2007-07-21$ \\
\hline Polyvinyl Chloride & $\mathrm{V}$ & DCE & $5 \mathrm{~T} / \mathrm{H}$ & $5 \mathrm{RMB} / \mathrm{T}$ & 5RMB & FGHJKMNQUVXZ & $\mathrm{N} / \mathrm{A}$ & 10th trading day & $2009-05-25$ \\
\hline Polypropylene & PP & DCE & $5 \mathrm{~T} / \mathrm{H}$ & $1 \mathrm{RMB} / \mathrm{T}$ & $0.6 \% \%$ & FGHJKMNQUVXZ & N/A & 10th trading day & 2014-02-28 \\
\hline Coke & $\mathrm{J}$ & $\mathrm{DCE}$ & $100 \mathrm{~T} / \mathrm{H}$ & $0.5 \mathrm{RMB} / \mathrm{T}$ & $0.6 \% \%$ & FGHJKMNQUVXZ & $21: 00-23: 30$ & 10th trading day & 2011-04-15 \\
\hline Coal & $\mathrm{JM}$ & DCE & $60 \mathrm{~T} / \mathrm{H}$ & $0.5 \mathrm{R} / \mathrm{T}$ & $0.6 \% \%$ & FGHJKMNQUVXZ & 21:00-23:30 & 10th trading day & 2013-03-22 \\
\hline Iron Ore & I & DCE & $100 \mathrm{~T} / \mathrm{H}$ & $0.5 \mathrm{R} / \mathrm{T}$ & $0.6 \% \%$ & FGHJKMNQUVXZ & 21:00-23:30 & 10th trading day & $2013-10-18$ \\
\hline Cotton & $\mathrm{CF}$ & $\mathrm{CZCE}$ & $5 \mathrm{~T} / \mathrm{H}$ & $5 \mathrm{RMB} / \mathrm{T}$ & $6 \mathrm{RMB}$ & FHKNUX & 21:00-23:30 & 10th trading day & $2004-06-01$ \\
\hline Sugar & $\mathrm{SR}$ & $\mathrm{CZCE}$ & $10 \mathrm{~T} / \mathrm{H}$ & $1 \mathrm{RMB} / \mathrm{T}$ & 3RMB & FHKNUX & 21:00-23:30 & 10th trading day & $2006-01-06$ \\
\hline PTA & $\mathrm{TA}$ & $\mathrm{CZCE}$ & $5 \mathrm{~T} / \mathrm{H}$ & $2 \mathrm{RMB} / \mathrm{T}$ & $3 \mathrm{RMB}$ & FGHJKMNQUVXZ & 21:00-23:30 & 10th trading day & $2006-12-18$ \\
\hline \multirow{2}{*}{ Canola Oil } & RO & $\mathrm{CZCE}$ & $5 \mathrm{~T} / \mathrm{H}$ & $2 \mathrm{RMB}$ & $\mathrm{N} / \mathrm{A}$ & FHKNUX & N/A & 10th trading day & $2007-06-08$ \\
\hline & OI & $\mathrm{CZCE}$ & $10 \mathrm{~T} / \mathrm{H}$ & $2 \mathrm{RMB} / \mathrm{T}$ & $2.5 \mathrm{RMB}$ & FHKNUX & $\mathrm{N} / \mathrm{A}$ & 10th trading day & $2015-05-15$ \\
\hline \multirow{2}{*}{ Methyl Alcohol } & $\mathrm{ME}$ & $\mathrm{CZCE}$ & $50 \mathrm{~T} / \mathrm{H}$ & 1RMB & N/A & FGHJKMNQUVXZ & N/A & 10th trading day & $2011-10-28$ \\
\hline & MA & $\mathrm{CZCE}$ & $10 \mathrm{~T} / \mathrm{H}$ & $1 \mathrm{RMB} / \mathrm{T}$ & 1.4RMB & FGHJKMNQUVXZ & $21: 00-23: 30$ & 10th trading day & $2015-05-15$ \\
\hline Glass & FG & $\mathrm{CZCE}$ & $20 \mathrm{~T} / \mathrm{H}$ & $1 \mathrm{RMB} / \mathrm{T}$ & 3RMB & FGHJKMNQUVXZ & 21:00-23:30 & 10th trading day & 2012-12-03 \\
\hline Rapeseed Dregs & $\mathrm{RM}$ & $\mathrm{CZCE}$ & $10 \mathrm{~T} / \mathrm{H}$ & $1 \mathrm{RMB} / \mathrm{T}$ & 1.5RMB & FHKNQUX & 21:00-23:30 & 10th trading day & $2012-12-28$ \\
\hline Silicon Manganese & SM & $\mathrm{CZCE}$ & $5 \mathrm{~T} / \mathrm{H}$ & $2 \mathrm{RMB} / \mathrm{T}$ & $3 \mathrm{RMB}$ & FGHJKMNQUVXZ & N/A & 10th trading day & 2014-08-08 \\
\hline Steam Coal & $\mathrm{ZC}$ & $\mathrm{CZCE}$ & $100 \mathrm{~T} / \mathrm{H}$ & $0.2 \mathrm{RMB} / \mathrm{T}$ & $4 \mathrm{RMB}$ & FGHJKMNQUVXZ & $\mathrm{N} / \mathrm{A}$ & 10th trading day & 2013-09-26 \\
\hline CSI300 index fut ures & $\mathrm{IF}$ & CFFEX & $300 \mathrm{RMB} / \mathrm{P}$ & $0.2 \mathrm{P}$ & $0.25 \% \%$ & FGHJKMNQUVXZ & $\mathrm{N} / \mathrm{A}$ & 3rd Friday & $2010-04-16$ \\
\hline CSI500 index fut ures & IC & CFFEX & 200RMB/P & $0.2 \mathrm{P}$ & $0.25 \% \%$ & FGHJKMNQUVXZ & $\mathrm{N} / \mathrm{A}$ & 3rd Friday & $2015-04-16$ \\
\hline SSE50 index fut ures & $\mathrm{IH}$ & CFFEX & $300 \mathrm{RMB} / \mathrm{P}$ & $0.2 \mathrm{P}$ & $0.25 \% \%$ & FGHJKMNQUVXZ & $\mathrm{N} / \mathrm{A}$ & 3rd Friday & $2015-04-16$ \\
\hline 5-year t-bond futures & $\mathrm{TF}$ & CFFEX & $10000 \mathrm{RMB} / \mathrm{P}$ & $0.005 \mathrm{RMB}$ & 3RMB & HMUZ & $\mathrm{N} / \mathrm{A}$ & 3 trading day after $2 r d$ Friday & 2013-09-06 \\
\hline 10-year t-bond fut ures & $\mathrm{T}$ & CFFEX & $10000 \mathrm{RMB} / \mathrm{P}$ & $0.005 \mathrm{RMB}$ & 3RMB & HMUZ & N/A & 3 trading day after 2 rd Friday & $2015-03-20$ \\
\hline
\end{tabular}

Notes: The letter codes are $F$ (January), $G$ (February), $H$ (March), $J$ (April), $K$ (May), $M$ (June), $N$ (July), $Q$ (August), $U$ (September), $V$ (October), $X$ (November) and $Z$ (December). All commodity futures are traded in a general day trading period of 9:00-10:15, 10:30-11:30 and 13:30-15:00. All index futures are traded in a general day trading period of 9:00-11:30 and 13:00-15:00. All bond futures are traded in a general day trading period of 9:15-11:30 and 13:00-15:15. Gold futures are traded with maturity in 3 nearest months and even months within 12 nearest months. Petroleum Asphalt are traded with maturity in 6 nearest months and season contract within 24 nearest months. All index futures are traded with maturity in 2 nearest natural months and two nearest season months. All bond futures are traded with maturity in 3 nearest season months (three consecutive months among March, June, September and December). 
Table 2: Descriptive statistics for the Chinese futures returns at different time intervals.

\begin{tabular}{|c|c|c|c|c|c|c|c|c|c|c|}
\hline ID & Mean & Std & Skew & Kurt & Min & Max & VaR Left & ES Left & VaR Right & ES Right \\
\hline $\mathrm{a}$ & -0.0003 & 0.0113 & 0.1162 & 5.622 & -0.0512 & 0.0474 & -0.0184 & -0.0256 & 0.0184 & 0.0266 \\
\hline ag & -0.0001 & 0.0128 & -0.3406 & 8.9788 & -0.0718 & 0.0518 & -0.0181 & -0.0306 & 0.0195 & 0.0308 \\
\hline al & 0.0005 & 0.0112 & 0.1090 & 4.7176 & -0.0405 & 0.0493 & -0.0184 & -0.0248 & 0.0183 & 0.0267 \\
\hline au & 0.0001 & 0.0086 & 0.5337 & 6.7461 & -0.0404 & 0.0453 & -0.0123 & -0.0171 & 0.0145 & 0.021 \\
\hline bu & -0.001 & 0.0202 & -0.3895 & 4.0211 & -0.0758 & 0.0666 & -0.0395 & -0.049 & 0.0298 & 0.0395 \\
\hline $\mathrm{c}$ & 0.0001 & 0.0098 & -0.0238 & 5.2623 & -0.0355 & 0.0364 & -0.015 & -0.0233 & 0.0153 & 0.0229 \\
\hline $\mathrm{CF}$ & 0.0003 & 0.0136 & 0.0663 & 6.069 & -0.068 & 0.0542 & -0.0203 & -0.0307 & 0.0234 & 0.0341 \\
\hline cs & -0.0004 & 0.0120 & 0.0992 & 4.1505 & -0.0497 & 0.0411 & -0.0203 & -0.0262 & 0.0198 & 0.0269 \\
\hline $\mathrm{cu}$ & 0.0003 & 0.0128 & 0.4080 & 6.8967 & -0.0577 & 0.0616 & -0.018 & -0.0276 & 0.0203 & 0.0311 \\
\hline $\mathrm{FG}$ & 0.001 & 0.0158 & 0.1243 & 4.3144 & -0.0521 & 0.0565 & -0.0268 & -0.0347 & 0.0274 & 0.0383 \\
\hline hc & 0.0012 & 0.0205 & -0.2090 & 4.983 & -0.079 & 0.0824 & -0.0314 & -0.0475 & 0.038 & 0.0463 \\
\hline $\mathrm{i}$ & 0.0016 & 0.0254 & -0.1142 & 3.7018 & -0.0763 & 0.0736 & -0.043 & -0.0564 & 0.0445 & 0.0566 \\
\hline IC & 0.0003 & 0.0273 & -0.6555 & 7.6112 & -0.1082 & 0.0975 & -0.0495 & -0.0783 & 0.0383 & 0.0634 \\
\hline IF & 0.0001 & 0.0209 & -0.7313 & 9.9247 & -0.1051 & 0.0954 & -0.0347 & -0.0594 & 0.0288 & 0.049 \\
\hline $\mathrm{IH}$ & -0.0001 & 0.0188 & -0.9307 & 12.719 & -0.1043 & 0.0957 & -0.0262 & -0.0524 & 0.0264 & 0.0434 \\
\hline $\mathrm{j}$ & 0.0023 & 0.0233 & -0.2224 & 5.4516 & -0.0989 & 0.0914 & -0.0357 & -0.0546 & 0.0446 & 0.0563 \\
\hline jd & -0.0006 & 0.0141 & 0.2166 & 5.1642 & -0.0531 & 0.0606 & -0.0229 & -0.0313 & 0.0236 & 0.0341 \\
\hline $\mathrm{jm}$ & 0.0017 & 0.0234 & -0.1334 & 4.6255 & -0.0867 & 0.0913 & -0.04 & -0.0532 & 0.0418 & 0.0531 \\
\hline 1 & 0.0005 & 0.0147 & 0.0811 & 4.7419 & -0.0554 & 0.0685 & -0.0229 & -0.033 & 0.0244 & 0.0336 \\
\hline $\mathrm{m}$ & 0.0003 & 0.0132 & 0.2254 & 4.4081 & -0.0466 & 0.0519 & -0.0212 & -0.0283 & 0.0227 & 0.0317 \\
\hline MA & 0.0001 & 0.0165 & -0.0172 & 3.8377 & -0.059 & 0.053 & -0.0263 & -0.036 & 0.0287 & 0.0361 \\
\hline $\mathrm{ni}$ & -0.0005 & 0.0159 & -0.3304 & 4.4157 & -0.0684 & 0.0575 & -0.029 & -0.0386 & 0.0238 & 0.0319 \\
\hline OI & 0 & 0.0106 & -0.0595 & 4.5672 & -0.0417 & 0.0381 & -0.0163 & -0.0237 & 0.0191 & 0.024 \\
\hline $\mathrm{p}$ & 0.0001 & 0.0134 & -0.1093 & 3.4672 & -0.0546 & 0.0381 & -0.0216 & -0.0284 & 0.0243 & 0.0282 \\
\hline $\mathrm{pp}$ & 0.0006 & 0.0155 & 0.1483 & 3.7077 & -0.0558 & 0.0521 & -0.0259 & -0.032 & 0.0291 & 0.036 \\
\hline $\mathrm{rb}$ & 0.0012 & 0.0213 & -0.0368 & 4.6485 & -0.079 & 0.0665 & -0.0342 & -0.048 & 0.0382 & 0.0503 \\
\hline RM & 0.0002 & 0.0158 & -0.0399 & 4.2647 & -0.0609 & 0.0562 & -0.0245 & -0.0357 & 0.0263 & 0.0358 \\
\hline $\mathrm{ru}$ & -0.0004 & 0.0216 & -0.3589 & 4.529 & -0.0755 & 0.0606 & -0.0395 & -0.0548 & 0.0347 & 0.0458 \\
\hline sn & 0.0003 & 0.0133 & -0.0086 & 4.0644 & -0.0453 & 0.0453 & -0.0227 & -0.0299 & 0.0235 & 0.0297 \\
\hline SR & 0 & 0.0089 & 0.2006 & 6.3912 & -0.0428 & 0.0417 & -0.0133 & -0.0189 & 0.0141 & 0.0209 \\
\hline $\mathrm{T}$ & 0.0001 & 0.0031 & -0.0927 & 7.5619 & -0.018 & 0.0157 & -0.0047 & -0.0071 & 0.0045 & 0.0072 \\
\hline TA & -0.0002 & 0.0130 & -0.3537 & 7.1047 & -0.0801 & 0.0501 & -0.0211 & -0.0306 & 0.02 & 0.0284 \\
\hline $\mathrm{TF}$ & 0 & 0.0021 & -0.0168 & 8.1985 & -0.0117 & 0.0109 & -0.0032 & -0.005 & 0.0031 & 0.0049 \\
\hline $\mathrm{v}$ & 0.0008 & 0.0133 & 0.1471 & 4.3812 & -0.0487 & 0.0473 & -0.0194 & -0.0281 & 0.0257 & 0.0323 \\
\hline $\mathrm{y}$ & 0 & 0.0106 & -0.1854 & 3.9582 & -0.0414 & 0.0369 & -0.0168 & -0.0231 & 0.0168 & 0.0214 \\
\hline $\mathrm{ZC}$ & 0.0009 & 0.0155 & -0.1103 & 4.3739 & -0.0576 & 0.0448 & -0.0252 & -0.035 & 0.0282 & 0.0356 \\
\hline $\mathrm{zn}$ & 0.0008 & 0.0153 & -0.0270 & 4.7273 & -0.0709 & 0.0575 & -0.0232 & -0.0325 & 0.0258 & 0.0349 \\
\hline
\end{tabular}

Notes: For all the products the normality of daily returns is rejected at the $95 \%$ confidence level via the Jarque-Bera and Anderson-Darling normality tests.

and short positions do not indicate the existence of a "gain/loss asymmetry", which is one of the stylized facts for stock returns as stated in [11]. Therefore, one might attribute the absence of "systematic gain/loss asymmetry" in the futures returns to the ease of taking short positions and the flexibility to use leverage. However, our main task in this study is to document these empirical facts and provide possible insight that might lead to future research rather than providing the comprehensive analysis for the causes of these empirical facts. 


\section{Futures Contract Maturity and Liquidity}

Several studies on the international futures market claim that the most liquid futures contracts are the nearest or second-nearest to maturity Miffre and Rallis (2007), Shen et al. (2007). However, this case is not common in the Chinese futures market, the nearest or second-nearest to maturity contract is always low-liquidity, i.e., the trading volume is nearly zero. The transaction costs to open long/short positions on the illiquid contracts are significantly high, and even the orders cannot be executed in some cases.

Table 3 displays the market activity for selected futures products with respect to trading days. Due to the limit of space, the trading information for futures products and trading days is partially documented and the market activity is consistent. Specifically, for the trading of Coke $(\mathrm{J})$ on the day of January 18, 2016, the nearest contract is J1602, since the exchange does not allow the traders to hold the position in maturity month. Panel A of Table 3 demonstrates that the trading liquidity is really low for the nearest contract (J1602) or the second-nearest contract (J1603), while more distance contracts (i.e., J1605 or J1609) are actively traded with respect to trading volume and open interest. Similarly, for the trading of Gold (AU) on the day of January 16, 2017, Panel B of Table 3 demonstrates that the contracts of AU1706 and AU1712 are actively traded contracts. Moreover, for the trading of Steam Coal (ZC) on the day of May 16, 2017, Panel C of Table 3 illustrates that the contracts of ZC709 and ZC801 are actively traded. Above all, it is demonstrated that the switching dates for the highest liquidity contracts (rollover dates) are not uniform for the Chinese futures, and the liquidity of one contract generally decreases before the expiry date approaches.

Table 4 reports the daily trading volume of Chinese futures with respect to the actively traded contracts, closest to maturity contracts and secondclosest to maturity contracts. The trading volume is documented in terms of minimum, maximum, mean and low liquidity in percentage. The low liquidity is identified by the daily trading volume less than 100 . The comparison shows that there are always some low liquidity cases for the nearest or second-nearest to maturity contract in the Chinese futures market. The average daily trading volume of the actively traded contract is apparently higher than that of the nearest or second-nearest to maturity contract. Furthermore, the consistent 
result is demonstrated in the comparison of minimum and maximum daily volumes. Therefore, it is reasonable to employ the actively traded contracts in this study, which is also suggested by the industry practitioners actively trading on the Chinese futures.

Since the objective of this study is providing practical suggestions both for the academia and practitioners, the most realistic framework is employed. According to the low-liquidity of the nearest or second-nearest contracts proposed by past studies Miffre and Rallis (2007), Shen et al. (2007), this study applies the self-complied dataset ${ }^{9}$ following the industry tradition, which is expected to provide the realistic and practical results.

For the consideration of roll-over returns, the daily log-returns are calculated from the close to pre-close prices when there is no roll-over between contracts, whereas if there is a roll-over happening, the return is obtained from the close to open price. The intuition behind this technique is that the holding positions would switch to the new active contract at the market open time. Additionally, the movement between the old and new active contracts occur regularly because most traders and CTAs appreciate short investment horizons (i.e. daily or few days) in the futures markets. This confirms that the financial industry does not pay much attention to the fixed roll-over rules, which is generally applied in the academic papers.

\section{Empirical Stylized Facts in the Chinese Fu- tures Markets}

There are quite significant differences between the stock and futures markets in China in the analysis of returns. There are a few dimensions of this difference which might lead to future research to explain the causes of empirical differences. One of the fundamental issues is the investor behavior and investment horizon. The stock market in China is well-known for its retail

\footnotetext{
${ }^{9}$ The most actively traded contract is identified by the trading volume and open interest after the market closed every day, if the contract with the maximum trading volume is same as the one with the maximum open interest, the underlying contract will be the main contract for the next trading day, otherwise, the contract with the further maturity month will be the main contract.
} 
Table 3: Market activity for selected futures products

\begin{tabular}{|c|c|c|c|c|c|c|c|c|}
\hline Contract & Pre. Settlement & Open & High & Low & Close & Settlement & Volume & Open Interest \\
\hline \multicolumn{9}{|c|}{ Panel A: Coke (J) on January 18, 2016} \\
\hline J1602 & 0.00 & 0.00 & 0.00 & 658.00 & 658.00 & 658.00 & 0 & 90 \\
\hline J1603 & 0.00 & 0.00 & 0.00 & 656.00 & 656.00 & 656.00 & 0 & 20 \\
\hline $\mathrm{J} 1604$ & 0.00 & 0.00 & 0.00 & 760.50 & 760.50 & 760.50 & 0 & 82 \\
\hline$\underline{\mathrm{J} 1605}$ & 625.00 & 640.50 & 622.50 & 639.00 & 627.50 & 634.00 & 227946 & 131530 \\
\hline J1606 & 622.00 & 640.00 & 622.00 & 640.00 & 632.00 & 629.50 & 8 & 4 \\
\hline $\mathrm{J} 1607$ & 0.00 & 0.00 & 0.00 & 606.00 & 608.00 & 606.00 & 0 & 8 \\
\hline J1608 & 0.00 & 0.00 & 0.00 & 624.50 & 626.50 & 624.50 & 0 & 2 \\
\hline J1609 & 608.00 & 624.50 & 606.00 & 624.00 & 613.00 & 617.50 & 23930 & 25512 \\
\hline $\mathrm{J} 1610$ & 0.00 & 0.00 & 0.00 & 627.50 & 623.00 & 627.50 & 0 & 4 \\
\hline J1611 & 615.50 & 615.50 & 607.00 & 608.00 & 603.50 & 611.00 & 10 & 26 \\
\hline J1612 & 620.00 & 620.00 & 619.50 & 619.50 & 619.50 & 619.50 & 4 & 6 \\
\hline $\mathrm{J} 1701$ & 598.50 & 618.00 & 558.00 & 618.00 & 603.50 & 610.50 & 500 & 214 \\
\hline Total & 0.00 & 0.00 & 0.00 & 0.00 & 0.00 & 0.00 & 252398 & 157498 \\
\hline \multicolumn{9}{|c|}{ Panel B: Gold (AU) on January 16, 2017} \\
\hline AU1701 & 269.00 & 0.00 & 0.00 & 0.00 & 269.00 & 269.00 & 0 & 372 \\
\hline AU1702 & 267.95 & 269.00 & 270.35 & 268.95 & 270.25 & 269.55 & 28 & 160 \\
\hline AU1703 & 268.50 & 269.35 & 270.50 & 267.95 & 269.25 & 269.30 & 18 & 16 \\
\hline AU1704 & 268.60 & 269.35 & 270.85 & 269.20 & 270.85 & 269.70 & 18 & 306 \\
\hline$\underline{\mathrm{AU} 1706}$ & 271.35 & 271.60 & 273.45 & 270.45 & 272.95 & 271.70 & 215196 & 382384 \\
\hline AU1708 & 271.55 & 272.50 & 274.30 & 272.50 & 274.05 & 272.65 & 74 & 176 \\
\hline AU1710 & 274.20 & 273.65 & 275.10 & 273.65 & 275.10 & 274.15 & 10 & 136 \\
\hline AU1712 & 273.90 & 274.40 & 276.60 & 273.40 & 276.00 & 275.00 & 3142 & 9334 \\
\hline Total & & & & & & & 218486 & 392884 \\
\hline \multicolumn{9}{|c|}{ Panel C: Steam Coal (ZC) on May 16, 2017} \\
\hline ZC706 & 563.60 & 555.00 & 574.40 & 554.40 & 574.40 & 564.60 & 8 & 26 \\
\hline $\mathrm{ZC707}$ & 541.60 & 0.00 & 0.00 & 0.00 & 0.00 & 541.60 & 0 & 0 \\
\hline ZC708 & 521.20 & 0.00 & 0.00 & 0.00 & 0.00 & 522.80 & 0 & 2 \\
\hline$\underline{\mathrm{ZC709}}$ & 510.80 & 510.80 & 522.00 & 508.00 & 521.60 & 514.40 & 187226 & 413674 \\
\hline ZC710 & 510.40 & 515.00 & 515.00 & 515.00 & 515.00 & 515.00 & 2 & 4 \\
\hline ZC711 & 517.00 & 0.00 & 0.00 & 0.00 & 0.00 & 522.40 & 0 & 2 \\
\hline $\mathrm{ZC} 712$ & 518.40 & 505.40 & 515.60 & 489.80 & 513.60 & 505.40 & 120 & 4 \\
\hline ZC801 & 516.60 & 517.80 & 526.80 & 514.20 & 526.60 & 519.60 & 7304 & 30772 \\
\hline ZC802 & 502.80 & 0.00 & 0.00 & 0.00 & 0.00 & 505.80 & 0 & 2 \\
\hline ZC803 & 529.80 & 0.00 & 0.00 & 0.00 & 0.00 & 529.80 & 0 & 0 \\
\hline ZC804 & 473.40 & 0.00 & 0.00 & 0.00 & 0.00 & 476.20 & 0 & 2 \\
\hline ZC805 & 493.60 & 491.60 & 497.00 & 491.20 & 497.00 & 493.20 & 98 & 236 \\
\hline Total & & & & & & & 194758 & 444724 \\
\hline
\end{tabular}

Notes: This table displays three examples (i.e., Coke, Gold and Steam Coal) in terms of market activity with respect to trading date in the Chinese market. The contract is represented by products ID plus maturity month, for example, J1602 denotes that the Coke futures $(\mathrm{J})$ with maturity in February of 2016. The trading information including the volume and open interest are documented. Prices with values of 0.00 mean that there is no trade for that contract. The nearest, second-nearest to maturity contracts and most actively traded contracts are highlighted in boldface and underline. The market data is downloaded from the exchange website,

http://www.dce.com.cn/dalianshangpin/xqsj/tjsj26/rtj/rxq/index.html (Coke-DCE),

http://www.shfe.com.cn/statements/dataview.html?paramid=kx (Gold-SHFE),

http://www.czce.com.cn/portal/DFSStaticFiles/Future/2017/20170516/FutureDataDaily.htm

(Steam 
Table 4: Trading volume for Chinese futures contracts

\begin{tabular}{|c|c|c|c|c|c|c|c|c|c|c|c|c|}
\hline \multirow{2}{*}{ Products } & \multicolumn{4}{|c|}{ Actively traded contracts } & \multicolumn{4}{|c|}{ Nearest to maturity } & \multicolumn{4}{|c|}{ Second-nearest to mat urity } \\
\hline & Minimum & Mean & Maximum & Low liquidity(\%) & Minimum & Mean & Maximum & Low liquidity(\%) & Minimum & Mean & Maximum & Low liquidity $(\%)$ \\
\hline SHFE.CU & 69828 & 350994 & 1319384 & 0 & 0 & 32602 & 119134 & 1 & 31072 & 238888 & 1162190 & 0 \\
\hline SHFE.AL & 14944 & 192030 & 1115798 & 0 & 0 & 14714 & 91942 & 1 & 5362 & 133633 & 574658 & 0 \\
\hline SHFE.ZN & 48202 & 419973 & 1844238 & 0 & 0 & 14891 & 186192 & 1 & 5620 & 302167 & 1844238 & 0 \\
\hline SHFE.NI & 25018 & 628741 & 2027096 & 0 & 0 & 15880 & 741862 & 50 & 0 & 138212 & 1870082 & 39 \\
\hline SHFE.SN & 68 & 16649 & 117778 & 1 & 0 & 1176 & 25734 & 73 & 0 & 4868 & 71278 & 69 \\
\hline SHFE.AU & 30714 & 219938 & 997696 & 0 & 0 & 2437 & 75806 & 80 & 0 & 25030 & 429826 & 70 \\
\hline SHFE.AG & 165778 & 664466 & 2777698 & 0 & 0 & 10672 & 441080 & 19 & 0 & 82078 & 1648032 & 28 \\
\hline SHFE.RB & 998326 & 5500228 & 22361440 & 0 & 0 & 13190 & 689884 & 30 & 14 & 236295 & 4923144 & 7 \\
\hline SHFE.HC & 4472 & 308160 & 1366450 & 0 & 0 & 1578 & 79242 & 82 & 0 & 32976 & 484316 & 71 \\
\hline SHFE.BU & 8870 & 935011 & 5742748 & 0 & 0 & 15653 & 765152 & $\begin{array}{l}59 \\
59\end{array}$ & 0 & 150070 & 2028104 & 51 \\
\hline SHFE.RU & 141414 & 630360 & 1621426 & 0 & 0 & 18449 & 640530 & 51 & 0 & 99645 & 1201474 & 52 \\
\hline DCE.C & 17562 & 695996 & 3723882 & 0 & 0 & 56931 & 1040962 & 40 & 0 & 260095 & 3723882 & 33 \\
\hline DCE.CS & 3930 & 375767 & 1386866 & 0 & 0 & 36416 & 611624 & 53 & 0 & 176413 & 1261036 & 49 \\
\hline DCE.A & 20452 & 194298 & 1299000 & 0 & 0 & 19511 & 279206 & 54 & 0 & 92892 & 663104 & 46 \\
\hline DCE.M & 390118 & 1952676 & 7651616 & 0 & 0 & 32604 & 1161044 & 57 & 0 & 340537 & 3964940 & 51 \\
\hline DCE.Y & 210586 & 581384 & 1394688 & 0 & 0 & 10926 & 374026 & 74 & 0 & 87106 & 739728 & 67 \\
\hline DCE.P & 121864 & 827984 & 2192238 & 0 & 0 & 1910 & 51800 & 82 & 0 & 59088 & 1696830 & 71 \\
\hline DCE.JD & 48652 & 168588 & 790810 & 0 & 0 & 19862 & 423418 & 63 & 0 & 27752 & 363510 & 38 \\
\hline DCE.L & 153042 & 662538 & 1945914 & 0 & 0 & 2260 & 79544 & 80 & 0 & 103922 & 1352510 & 72 \\
\hline DCE.V & 1572 & 91559 & 498204 & 0 & 0 & 611 & 25498 & 84 & 0 & 21480 & 498204 & 72 \\
\hline DCE.PP & 137190 & 722099 & 3628622 & 0 & 0 & 4378 & 274624 & 78 & 0 & 135841 & 2112582 & 71 \\
\hline DCE.J & 17314 & 243581 & 2420704 & 0 & 0 & 1738 & 150056 & 80 & 0 & 32926 & 663158 & 71 \\
\hline DCE.JM & 23972 & 222440 & 1508004 & 0 & 0 & 1245 & 100394 & 81 & 0 & 28781 & 492422 & 72 \\
\hline DCE.I & 488242 & 2246292 & 7526732 & 0 & 0 & 12118 & 458882 & 72 & 0 & 269589 & 4856536 & 56 \\
\hline CZCE.CF & 34264 & 325614 & 2864938 & 0 & 0 & 20353 & 508568 & 19 & 0 & 115618 & 1180982 & 27 \\
\hline CZCE.SR & 148700 & 822613 & 3360972 & 0 & 0 & 79357 & 2168962 & 31 & 0 & 395816 & 3193876 & 45 \\
\hline CZCE.TA & 192418 & 1270270 & 4321300 & 0 & 0 & 7881 & 211338 & 72 & 0 & 177029 & 2478650 & 68 \\
\hline CZCE.OI & 19212 & 136881 & 803722 & 0 & 0 & 14978 & 319112 & 53 & 0 & 64611 & 641318 & 51 \\
\hline CZCE.MA & 254140 & 1248577 & 4409694 & 0 & 0 & 3516 & 102282 & 78 & 0 & 189873 & 3226926 & 71 \\
\hline CZCE.FG & 60644 & 401266 & 1918260 & 0 & 0 & 1641 & 201664 & 82 & 0 & 65970 & 764546 & 68 \\
\hline CZCE.RM & 232564 & 1434127 & 6092828 & 0 & 0 & 65864 & 1771172 & 48 & 0 & 397072 & 4619488 & 37 \\
\hline CZCE.ZC & 2350 & 227308 & 1700950 & 0 & 0 & 6567 & 219306 & 79 & 0 & 52621 & 838992 & 71 \\
\hline CFFEX.IF & 4154 & 239112 & 2882235 & 0 & 0 & 226271 & 2882235 & 1 & 95 & 31318 & 2340449 & 0 \\
\hline CFFEX.IC & 2196 & 37508 & 502523 & 0 & 0 & 35375 & 502523 & 1 & 102 & 5714 & 385745 & 0 \\
\hline CFFEX.IH & 0 & 51185 & 861208 & 1 & 0 & 49071 & 861208 & 1 & 0 & 6699 & 464391 & 3 \\
\hline CFFEX.TF & 1453 & 12195 & 75239 & 0 & 0 & 9637 & 75239 & 12 & 41 & 4321 & 44662 & 1 \\
\hline CFFEX.T & 1235 & 25215 & 109383 & 0 & 0 & 17496 & 109383 & 12 & 28 & 11312 & 75352 & 2 \\
\hline
\end{tabular}

Notes: This table displays the daily trading volumes for the Chinese futures during 2015-05-22 to 2017-08-09. The product is identified by trading exchanges plus futures ID, for example, DCE.J denotes that the Coke futures $(\mathrm{J})$ traded in the Dalian Commodity Exchange (DCE). The daily trading volume is reported including the minimum, maximum, mean and low liquidity in terms of percentage. The low liquidity trading day is recorded when the daily trading volume is less than 100, which implies that the contract is really illiquid. The trading volume data is downloaded from the exchange website, http://www.dce.com.cn (DCE), http://www.shfe.com.cn (SHFE), http://www.czce.com.cn (CZCE), http://www.cffex.com.cn (CFFEX), respectively. 
character, whereas futures markets are dominated by the hedge funds and futures companies. The futures contracts are mainly traded by the hedge funds or the CTAs for short holding periods of time ${ }^{10}$. There is clear economic intuition behind this investor behavior in comparison to the stock markets since the invested asset does not involve any cash flow or revenue generating activity as in the case of stocks. Therefore, hedge funds and CTAs, with very dynamic and short term investment strategies, are dominant in the futures markets.

\subsection{Serial Correlation in Futures Returns}

As stated in [11]: "(linear) auto-correlations of asset returns are often insignificant, except for very small intra-day time scales ( $\sim 20$ minutes) for which micro-structure effects come into play." Overall, for the stock markets the serial correlation is not significant at least for the daily time horizon, where the opposite result yields the conclusion of inefficiency in the market. We check for the existence of serial correlation in the futures returns, and find that at the daily horizon there are no significant serial correlations for the vast majority of the products. If one can demonstrate the existence of serial correlation for an asset, this implies the inherent statistically significant predictability and the failure of market efficiency assumptions.

In Table 5, $p$-values obtained from the Ljung-Box test are given for the mean subtracted log-returns and also for the squared returns to verify potential serial correlation in the returns or squared returns ${ }^{11}$. The results show that, for most of the products, the serial correlation is rejected at the $95 \%$ confidence level with the exception of few cases. In the Chinese market, the serial correlation problem is more severe for the futures on stock market indices. This might not be surprising given the fact that the index futures have special restrictions implemented since the Summer 2015 financial turmoil in China when the new restrictions for index futures were introduced. Setting

\footnotetext{
${ }^{10}$ Feedback we received from various hedge funds such as JinYiBao Ltd. and the Hedge Fund Research Center at SAIF indicates that, although there are variations in the investment horizon of different funds due to the high leverage in the industry, inta-day or few days (1-5 days) holding period is the most typical investment horizon in the Chinese futures markets.

${ }^{11}$ Last five lag values are used for testing the serial correlation, however, results with different lags are similar and often the lags that are within the last five trading days are often more significant than the previous ones.
} 
Table 5: Testing for the serial correlation in the log-returns and absolute value of log-returns in the Chinese futures markets.

\begin{tabular}{c|ccccccccccccccccccc}
\hline ID & a & ag & al & au & bu & c & CF & cs & cu & FG & hc & i & IC & IF & IH & j & jd & jm & 1 \\
$r_{t}$ & 0.09 & 0.38 & 0.54 & 0.72 & 0.58 & 0.65 & 0.49 & 0.51 & 0.02 & 0.50 & 0.39 & 0.09 & 0.00 & 0.00 & 0.00 & 0.60 & 0.29 & 0.19 & 0.12 \\
$\left|r_{t}\right|$ & 0.05 & 0.65 & 0.02 & 0.49 & 0.45 & 0.13 & 0.00 & 0.02 & 0.00 & 0.12 & 0.00 & 0.00 & 0.00 & 0.00 & 0.00 & 0.00 & 0.15 & 0.00 & 0.27 \\
\hline \hline
\end{tabular}

This table illustrates the Ljung-Box serial correlation test results with the log-returns and squared log-returns with the p-values of the test results presented. P-values less then $5 \%$ level indicates the rejection of the null hypothesis of "no serial correlation".

aside the special case of the index futures, for most of the futures returns, serial correlations are weak for the daily horizon. However, when the high frequency returns such as the 1 to 15 minute return frequencies are considered, the microstructure effects come into play and we observe significant serial correlation in returns. For the 15 to 30 minute returns, for almost all the products, the last one lag shows significant serial correlation. This can be interpreted as a result of the trend-following strategies that are implemented by traders in the intra-day trading activities. Overall, in the Chinese futures markets the serial correlation of returns is more pronounced at the high-frequencies due to the trading behavior of investors. At frequencies higher than the five minute level, the micro-structure effect, in particular the "bid-ask bounce" reveals itself as the dominant behavior (i.e. revealing itself as the significant negative serial correlation for the first lag of the returns).

In Figure 2, we plot the sample partial auto-correlation function for the stock index futures (IH, IF, and IC) returns and for the absolute value of these returns. Additional to the partial auto-correlation of returns, the absolute value of these returns are verified for the existence volatility clustering. It can be noted that the stock index futures exhibit significant serial correlation both in the returns and absolute value of returns, and this effect is more pronounced than the commodity and bond futures in the market. Similarly, in Figures 3 and 4, we plot the sample partial auto-correlation function for the five and ten year bond futures ( $\mathrm{T}$ and $\mathrm{TF}$ ), respectively. Different from the index futures, bond futures returns do not show significant serial correlation in the returns, but show serial correlation for the absolute value of returns and thus volatility 

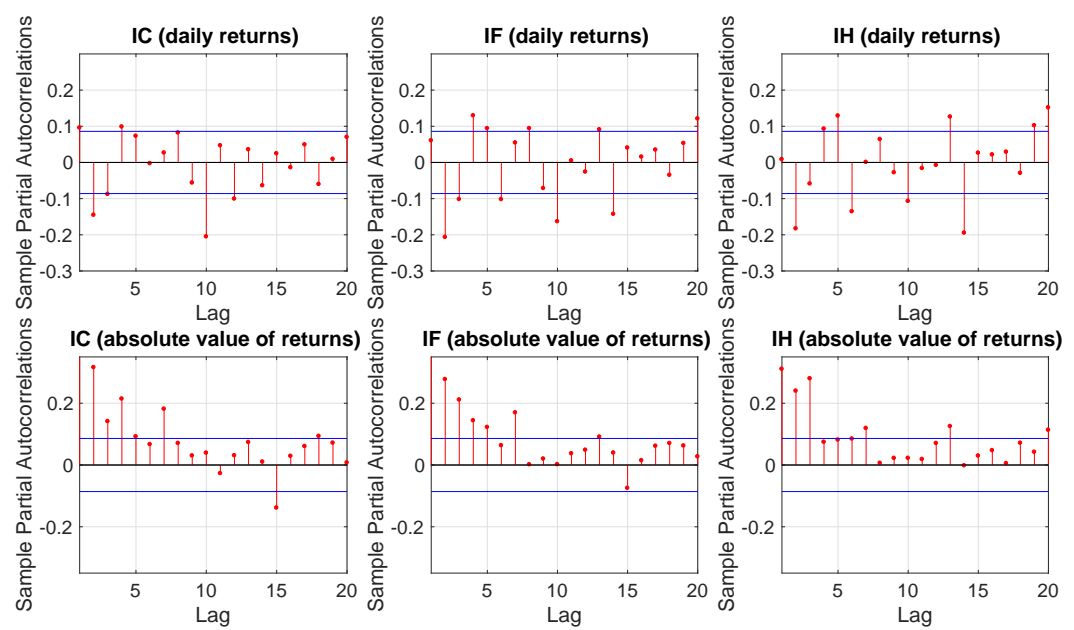

Figure 2: Partial autocorrelations of close-to-close futures returns.

clustering effect is observed similar to the index futures. The special feature of the index futures can be explained with the special restrictions imposed by the regulators on the number of contracts index futures can be traded. Therefore, it should not be surprising to observe that the index futures have stronger serial correlation in the returns, which also implies the existence of inefficiencies in the price discovery function of these products.

When we check the high frequency of returns, such as the 1, 5, 15, and 30 minute intervals, the serial correlation is often higher due to the microstructure effects as in the case of stock returns. Due to the "bid-ask bounce" we often observe the negative serial correlation in the first lag for all the futures. This phenomenon also exist in equity markets as a stylized fact as well (see [11]). As an example, we plot the minute level partial auto-correlation function for the soybean futures as given in Figure 5. At the high frequency returns there is stronger volatility clustering effect and as a typical representative we plot the partial autocorrelation function of the squared residuals for the soybean futures as given in Figure 5. Quite similar plots are obtained for the all the futures return series of other products, however, these are not presented here for brevity. Overall, it should be noted that the stock index futures show more pronounced serial correlation compared to the bond and commodity futures. This might be explained by the fact that index futures have severe restrictions in the market in terms of the number of contracts the investors can long or short. This restriction simply means that the market can 

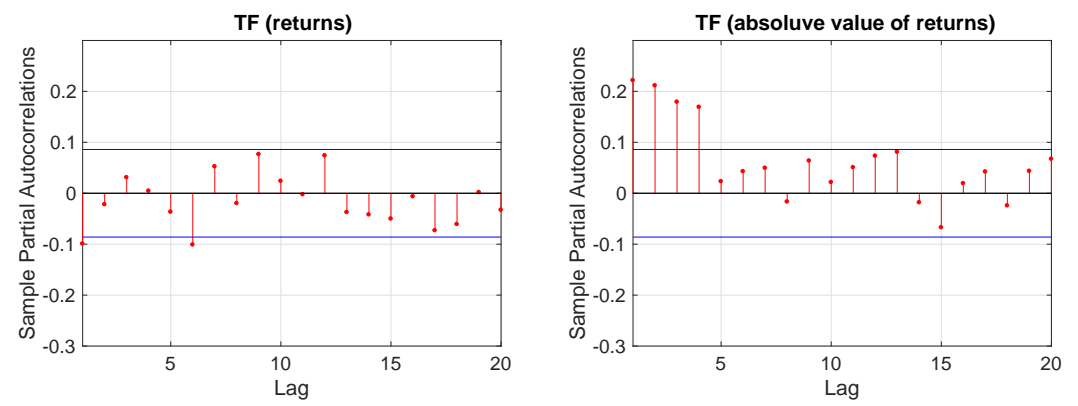

Figure 3: Partial autocorrelations of close-to-close futures returns.

not trade as much as it is needed to fully reflect the market's price expectation on the financial indices efficiently.

Volatility clustering is one of the main characteristics of the daily stock returns data in most of the markets, which is also documented for the Chinese stock markets (e.g. [12] and [17]). The same phenomena is not only observed with higher frequency of returns, such as minute level returns, but also at the lower frequencies such as monthly returns (see [23]). Volatility clustering effect can be visually inspected via the partial auto-correlation function for the squared or absolute returns (see [35]), whereas the results in Table 5 presents the Ljung-Box serial correlation test for absolute returns. Statistical analysis on the PACF and ACF of the futures returns indicate that financial futures exhibit strong serial correlation problem in comparison to the commodity futures returns. Therefore, to understand the behavior of volatility in returns we employ different GARCH specifications in the rest of the article.

Similar to the issue of serial correlation in returns index futures, i.e. IF, $\mathrm{IH}$, and IC, exhibit much stronger volatility clustering effects in the first few lags of all the three types of return time series as can be seen in Table 5 and in Figure 2. Furthermore, bond futures exhibit stronger volatility clustering and GARCH effects in the first few lags as well, whereas commodity futures in general do not show volatility clustering effects as strong as the financial futures. Table 5 shows the results of the Ljung-Box test applied for the residuals and the squared residuals testing for the significance of serial correlation and $\mathrm{ARCH} / \mathrm{GARCH}$ effects in the return series, respectively. Overall, for the daily log-returns, a few of the commodity futures indicate strong serial correlation of absolute values of returns and thus volatility clustering effects. 

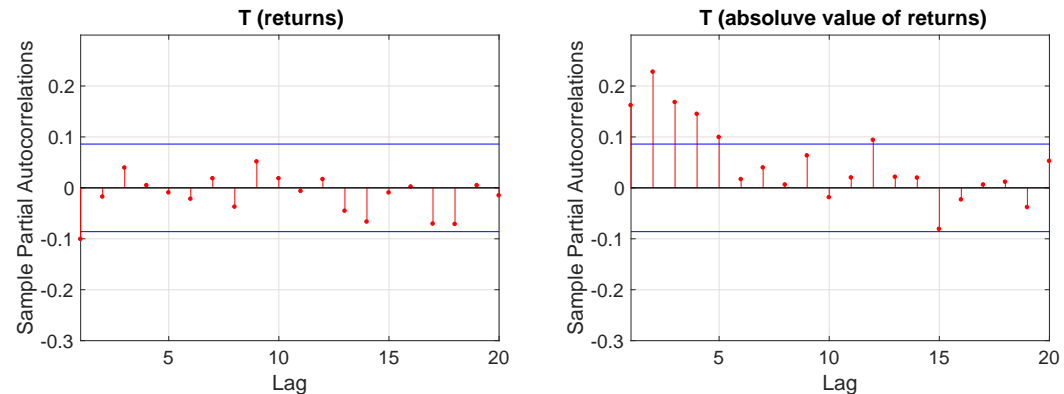

Figure 4: Partial autocorrelations of close-to-close futures returns.
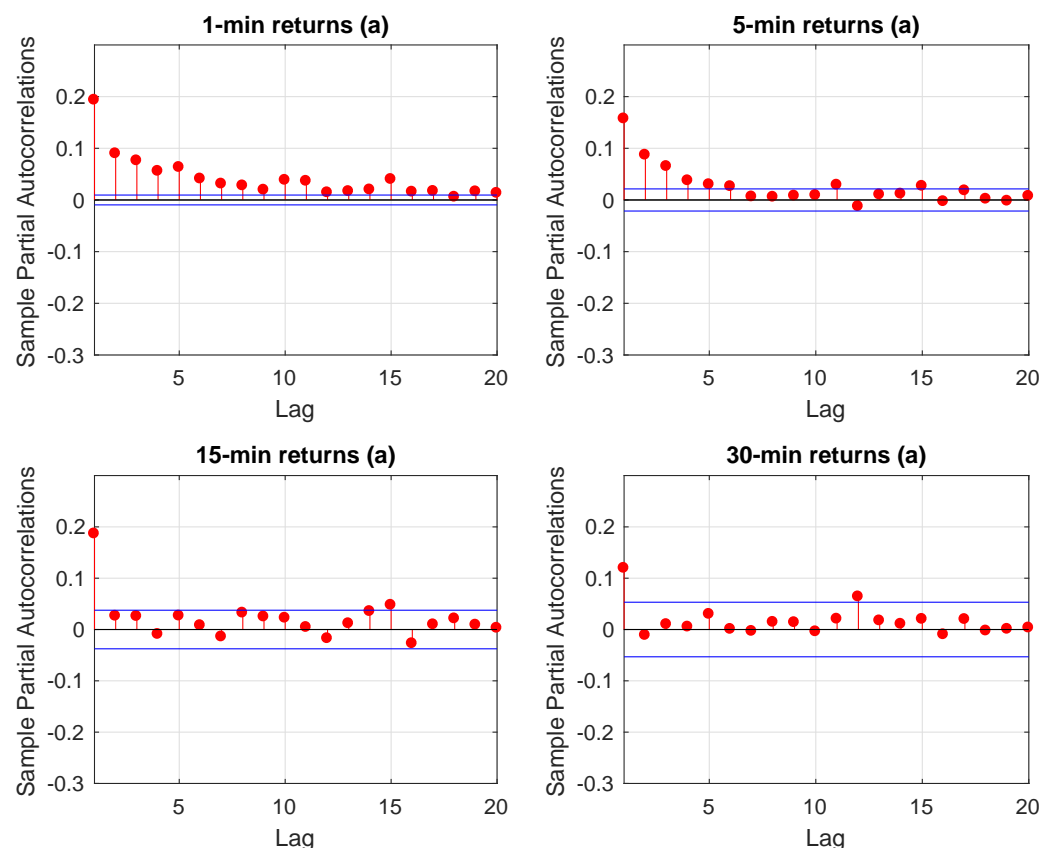

Figure 5: Sample partial autocorrelation plotted for the soybean futures logreturns at different time intervals. 


\subsection{Testing for Unit Root}

Financial time series exhibit trending behavior or non-stationarity in the mean, where it is an important task of the financial econometricians to determine the most appropriate form of the trend term in the data. If the data exhibit trend, then two common trend removal techniques are employed. For time series of integrated with order one, i.e. $I(1)$, whereas time-trend regression is appropriate for trend stationary $I(0)$ time series. Unit root tests can be used to determine if the trending data should be first differenced or regressed on a deterministic trend term to render the data stationary. Moreover, two non-stationary financial time series might exhibit stationarity when linear combinations of these two times series is considered. If these variables are integrated of order one, i.e. $I(1)$, then co-integration techniques can be used. In this rest of the article, the existence of co-integration is also tested.

The tests for unit roots in the univariate time-series of the daily prices are implemented using three different specifications of the Augmented Dickey Fuller test ${ }^{12}$. As the general conclusion on the unit roots in the Chinese futures markets we show that the unit root hypothesis can be rejected in some cases for the log-price series and the rejection depends on the assumption of the alternative hypothesis.

In the auto-regressive model variant $(\mathrm{AR})$ of the unit root testing procedure (see [35] for details on unit root tests), we are testing the null model

$$
y_{t}=y_{t-1}+\epsilon_{t}
$$

against the alternative model

$$
y_{t}=\varphi y_{t-1}+\epsilon_{t},
$$

with $\operatorname{AR}(1)$ coefficient, $\varphi<1$. This the original unit root test, which can be applied for a random walk without any drift term. However, this model is too simple to represent the real data. The economic or financial data might include a trend term.

The auto-regressive model with drift variant (denoted as ARD) supposes a test of the null model

$$
y_{t}=y_{t-1}+\epsilon_{t}
$$

\footnotetext{
${ }^{12}$ Augmented Dickey Fuller test is implemented using the "adftest(.)" function in MATLAB with the null hypothesis of the existence of a unit root.
} 
against the alternative model

$$
y_{t}=c+\varphi y_{t-1}+\epsilon_{t},
$$

with drift coefficient $c$, and the $\operatorname{AR}(1)$ coefficient, $\varphi<1$. This model is given by [30], which argues that most macroeconomic time series display a unit root phenomenon with a stochastic trend. This property is described as "difference stationary" (DS) so that the first difference of this kind of time series is stationary.

[33] argues that most macroeconomic time series are characterized by the "trend stationary" (TS) model, if structural changes in the trend function is allowed. In Perron's paper, the test is given by

$$
y_{t}=c+y_{t-1}+\epsilon_{t}
$$

against the alternative model

$$
y_{t}=c+\delta t+\varphi y_{t-1}+\epsilon_{t},
$$

with drift coefficient $c$, deterministic trend coefficient $\delta$, and $\operatorname{AR}(1)$ coefficient, $\varphi<1$. In this paper, all of the three methodologies of unit roots tests are employed. Table 6 shows the test results in terms of p-values for the total of 37 products in the Chinese futures market. The results show that for the CSI500 index futures (IC), the null hypothesis in the AR model is rejected, whereas for corn starch (cs) and PTA (TA), the null hypothesis in the ARD model is rejected. For glass (FG), CSI500 index futures (IC), and CSI300 index futures (IF), the null hypothesis in the TS model is rejected.

Overall, the necessary condition for the random walk hypothesis is rejected for a few commodities given the three types of model specifications considered for the log-price time series. However, as well-known market efficiency is a concept that is not directly testable (see [16]) due to the joint hypothesis problem. According to [16], most long- term anomalies are also sensitive to the statistical methodology utilized. We show that at least for a few products, the unit root, which is a pre-requisite for the random walk hypothesis, can be rejected. Therefore, potential inefficiencies in the market might be exploitable via trading strategies to generate statistical arbitrage profits. For a general discussion on the market efficiency and statistical arbitrage strategies we refer to the work of $[20]$. 
Table 6: Unit root test for main contracts.

\begin{tabular}{cccccccc}
\hline Products & TS & AR & ARD & Products & TS & AR & ARD \\
\hline $\mathrm{a}$ & 0.30 & 0.50 & 0.08 & $\mathrm{ag}$ & 0.51 & 0.10 & 0.40 \\
$\mathrm{al}$ & 0.25 & 0.51 & 0.92 & $\mathrm{au}$ & 0.59 & 0.30 & 0.59 \\
$\mathrm{bu}$ & 0.50 & 0.67 & 0.05 & $\mathrm{c}$ & 0.06 & 0.07 & 0.33 \\
$\mathrm{CF}$ & 0.64 & 0.41 & 0.74 & $\mathrm{cs}$ & 0.15 & 0.57 & $0.04^{*}$ \\
$\mathrm{cu}$ & 0.26 & 0.27 & 0.72 & $\mathrm{FG}$ & $0.03^{*}$ & 0.88 & 0.88 \\
$\mathrm{hc}$ & 0.23 & 0.73 & 0.95 & $\mathrm{i}$ & 0.50 & 0.81 & 0.89 \\
$\mathrm{IC}$ & $0.05^{*}$ & $0.04^{*}$ & 0.24 & $\mathrm{IF}$ & $0.03^{*}$ & 0.19 & 0.26 \\
$\mathrm{IH}$ & 0.06 & 0.32 & 0.12 & $\mathrm{j}$ & 0.46 & 0.97 & 0.98 \\
$\mathrm{jd}$ & 0.29 & 0.70 & 0.45 & $\mathrm{jm}$ & 0.48 & 0.89 & 0.93 \\
$\mathrm{l}$ & 0.38 & 0.50 & 0.73 & $\mathrm{~m}$ & 0.59 & 0.40 & 0.58 \\
$\mathrm{MA}$ & 0.39 & 0.26 & 0.64 & $\mathrm{ni}$ & 0.31 & 0.60 & 0.06 \\
$\mathrm{OI}$ & 0.62 & 0.06 & 0.36 & $\mathrm{p}$ & 0.36 & 0.15 & 0.56 \\
$\mathrm{pp}$ & 0.66 & 0.61 & 0.87 & $\mathrm{rb}$ & 0.17 & 0.69 & 0.95 \\
$\mathrm{RM}$ & 0.44 & 0.14 & 0.36 & $\mathrm{ru}$ & 0.66 & 0.34 & 0.42 \\
$\mathrm{sn}$ & 0.19 & 0.39 & 0.87 & $\mathrm{SR}$ & 0.40 & 0.10 & 0.46 \\
$\mathrm{~T}$ & 0.75 & 0.45 & 0.41 & $\mathrm{TA}$ & 0.08 & 0.23 & $0.02^{*}$ \\
$\mathrm{TF}$ & 0.66 & 0.35 & 0.47 & $\mathrm{v}$ & 0.45 & 0.74 & 0.94 \\
$\mathrm{y}$ & 0.69 & 0.09 & 0.40 & $\mathrm{ZC}$ & 0.28 & 0.88 & 0.99 \\
$\mathrm{zn}$ & 0.22 & 0.71 & 0.95 & & & & \\
\hline & & & & & & &
\end{tabular}




\subsection{Distributional Properties}

One of the well-documented stylized facts in the analysis of stock market returns is the violation of the normality. There are three distributional stylized facts that applies to stock returns. First, the distribution of stock returns do not follow normal distribution, however, aggregational Gaussianity is often observed. That is, at the lower frequency of returns such as the weekly or monthly frequencies, stock returns get closer to the normal distribution, whereas for the high frequency returns such as the minute level returns, the lepto-kurtosis is more pronounced. Finally, stock returns exhibit distributions with negative skewness implying that the likelihood of having large negative returns is higher than having large positive returns (see [11] for details).

Based on these three major distributional properties of stock returns we analyze the futures returns. First, we test the normality of the futures returns calculated for each of the products at the daily and weekly frequencies. To verify the normality assumption, we consider three types of statistical tests, namely, Anderson-Darling goodness-of-fit test, Jarque-Bera normality test and the chi-square goodness-of-fit test. For brevity we do not present all the test statistics since normality can be clearly rejected for all the products. We conclude that the normal distribution is rejected for all the futures returns at the daily and minute level timescales.

Alternatively, t-location scale distribution is fitted for all the futures returns as presented in Table 7. [32], [6] and [4] suggest that the Student's $t$ distribution is a suitable distribution with high peak and fat tails to model the futures returns. Therefore, additional to testing the normality of futures returns, we test the $t$ location-scale distribution, which is known to provide a better fit compared to the normal distribution for the case of stock returns. The same behavior is observed for the case of futures returns in terms the goodness-of-fit tests.

Furthermore, the Chi-square goodness-of-fit test ${ }^{13}$ is implemented with the daily and weekly log-returns of the futures products. The log-returns are calculated removing the effect of the contract roll-overs as discussed in the data section. The results obtained are given in Table 7 with the p-values of the test. A $p$-value of lower than 0.05 indicates the rejection of the null

\footnotetext{
${ }^{13}$ This test is implemented using the "chisquare(.)" goodness-of-fit function in MATLAB and similar built-in functions exist in other statistical software as well.
} 
hypothesis, which is the assumed distributions of normal and $t$-location scale distributions, respectively. Similar to the results with the Anderson-Darling and Jarque-Bera test statistics not presented here, Chi-square statistics also reject the normality assumption for all the products except for three products with tickers "MA, p, and y" for the daily frequency of returns. However, for the weekly frequency the $p$-values tend to increase for most of the products, and thus aggregational Gaussianity principle comes into play as in the case of stock returns. Looking to Table 7 , it can be noted that the $t$-location scale distribution clearly provides a better fit and the $t$ location scale distribution can be rejected for only 8 products out of 37 , namely "bu, hc, IC, jm, ni, rb, $\mathrm{v}$, and ZC".

To provide a visual inspection of the goodness-of-fit the empirical daily log-returns are plotted together with the fitted normal and $t$ location scale distributions in Figure 6. Figure 6 shows that the $t$ location-scale distribution fits the futures returns better than the normal distribution, which is consistent with the observation of the excess kurtosis and fat tails. Table 8 confirms the existence of fat tails with the estimated degrees of freedom parameter $\nu$ in the $t$ Location-Scale distribution. It can also be noted that the estimated values are higher in the weekly case indicating the tendency for aggregational Gaussianity and weakening of the fat tails over the longer time horizons. Results show in only a few products we reject the $t$ location-scale distribution as the null hypothesis.

As a consequence of non-uniform skewness behavior across different products, Value-at-Risk (VaR) estimates for both sides of the tail are often close. In general, there is no evidence to show that the VaR values for the left tail are larger than the estimated values for the right tail as can be seen in Table 2. A general conclusion on negative skewness is not possible as a stylized fact of futures returns. The behavior of skewness is closely related to the momentum trading in different products, which implies that during bullish periods of the product positive skewness is common, whereas during the bearish periods negative skewness is more common.

In summary there are three stylized facts for the log-returns of futures contracts, which is also common for the stock returns. These are the nonnormality of log-returns and the aggregational Gaussianity properties. On the other hand, the negative skewness commonly observed in stock returns is 
Table 7: Chi-square tests results for normal and t Location-Scale distribution for daily and weekly returns (p-value).

\begin{tabular}{|c|c|c|c|c|}
\hline \multirow{2}{*}{$\begin{array}{l}\text { Frequency } \\
\text { Distribution }\end{array}$} & \multicolumn{2}{|c|}{ Daily Returns } & \multicolumn{2}{|c|}{ Weekly Returns } \\
\hline & Normal & t Location-Scale & Normal & t Location-Scale \\
\hline $\mathrm{a}$ & $0.00^{*}$ & 0.49 & 0.34 & 0.19 \\
\hline $\mathrm{ag}$ & $0.00 *$ & 0.24 & 0.11 & 0.17 \\
\hline al & $0.00 *$ & 0.16 & 0.12 & 0.43 \\
\hline au & $0.00 *$ & 0.07 & 0.08 & $0.04 *$ \\
\hline bu & $0.00 *$ & $0.00^{*}$ & 0.46 & 0.31 \\
\hline $\mathrm{c}$ & $0.00^{*}$ & 0.32 & 0.65 & 0.68 \\
\hline $\mathrm{CF}$ & $0.00 *$ & 0.58 & $0.00^{*}$ & 0.51 \\
\hline cs & $0.00 *$ & 0.65 & 0.12 & 0.06 \\
\hline $\mathrm{cu}$ & $0.00 *$ & 0.90 & 0.10 & 0.05 \\
\hline FG & $0.00 *$ & 0.09 & 0.44 & 0.28 \\
\hline hc & $0.00 *$ & $0.00 *$ & 0.29 & 0.77 \\
\hline $\mathrm{i}$ & $0.00 *$ & 0.12 & $0.04^{*}$ & $0.01^{*}$ \\
\hline IC & $0.00 *$ & $0.02^{*}$ & $0.00^{*}$ & $0.05^{*}$ \\
\hline IF & $0.00^{*}$ & 0.18 & $0.03^{*}$ & 0.26 \\
\hline $\mathrm{IH}$ & $0.00 *$ & 0.29 & $0.01^{*}$ & 0.27 \\
\hline $\mathrm{j}$ & $0.00 *$ & 0.33 & $0.02 *$ & $\mathrm{NaN}$ \\
\hline jd & $0.00 *$ & 0.14 & 0.40 & 0.27 \\
\hline $\mathrm{jm}$ & $0.00^{*}$ & $0.00^{*}$ & 0.23 & 0.14 \\
\hline 1 & $0.00 *$ & 0.06 & 0.17 & 0.10 \\
\hline $\mathrm{m}$ & $0.00 *$ & 0.24 & 0.53 & 0.36 \\
\hline MA & 0.17 & 0.98 & 0.19 & 0.10 \\
\hline ni & $0.00 *$ & $0.00^{*}$ & $0.02^{*}$ & $0.01 *$ \\
\hline OI & $0.00^{*}$ & 0.75 & 0.16 & 0.09 \\
\hline $\mathrm{p}$ & 0.58 & 0.68 & 0.40 & 0.25 \\
\hline $\mathrm{pp}$ & $0.00^{*}$ & 0.06 & 0.75 & 0.63 \\
\hline $\mathrm{rb}$ & $0.00^{*}$ & $0.02^{*}$ & $0.03^{*}$ & $\mathrm{NaN}$ \\
\hline $\mathrm{RM}$ & $0.00 *$ & 0.38 & 0.19 & 0.12 \\
\hline $\mathrm{ru}$ & $0.00 *$ & 0.17 & 0.91 & 0.84 \\
\hline sn & $0.00 *$ & 0.13 & 0.93 & 0.85 \\
\hline SR & $0.01^{*}$ & 0.31 & 0.16 & 0.15 \\
\hline $\mathrm{T}$ & $0.00^{*}$ & 0.40 & 0.15 & 0.49 \\
\hline $\mathrm{TA}$ & $0.00^{*}$ & 0.41 & 0.48 & 0.35 \\
\hline $\mathrm{TF}$ & $0.00 *$ & 0.77 & $0.00^{*}$ & $\mathrm{NaN}$ \\
\hline $\mathrm{v}$ & $0.00^{*}$ & $0.01^{*}$ & $0.05^{*}$ & $0.02^{*}$ \\
\hline $\mathrm{y}$ & 0.24 & 0.22 & 0.13 & 0.07 \\
\hline $\mathrm{ZC}$ & $0.00^{*}$ & $0.00^{*}$ & 0.20 & 0.10 \\
\hline $\mathrm{zn}$ & $0.01^{*}$ & 0.47 & 0.40 & 0.26 \\
\hline
\end{tabular}

* represents significant on $5 \%$ level, NaN represents the p-value approaches 1 . 
Table 8: Parameter estimates for the $t$-Location-Scale distribution for the for daily and weekly futures returns.

\begin{tabular}{|c|c|c|c|c|c|c|}
\hline \multirow[b]{2}{*}{ ID } & \multicolumn{3}{|c|}{ Daily Returns } & \multicolumn{3}{|c|}{ Weekly Returns } \\
\hline & $\mu$ & $\sigma$ & $\nu$ & $\mu$ & $\sigma$ & $\nu$ \\
\hline a & -0.0006 & 0.0077 & 3.3517 & -0.0032 & 0.0213 & $>20$ \\
\hline ag & -0.0003 & 0.0069 & 2.3158 & -0.0038 & 0.0227 & 3.9259 \\
\hline al & 0.0004 & 0.0084 & 4.1956 & -0.0001 & 0.0181 & 4.8928 \\
\hline $\mathrm{au}$ & -0.0002 & 0.0063 & 4.1074 & 0.0013 & 0.0219 & $>20$ \\
\hline bu & 0.0001 & 0.0157 & 4.6105 & -0.0111 & 0.0418 & $>20$ \\
\hline c & 0.0001 & 0.0067 & 3.3306 & -0.0017 & 0.0171 & 7.1093 \\
\hline $\mathrm{CF}$ & 0.0001 & 0.0084 & 2.7567 & -0.0005 & 0.0148 & 1.8196 \\
\hline $\mathrm{cs}$ & -0.0005 & 0.0099 & 6.0903 & -0.0049 & 0.0244 & 8.7613 \\
\hline $\mathrm{cu}$ & 0.0000 & 0.0088 & 3.5875 & -0.0020 & 0.0227 & $>20$ \\
\hline FG & 0.0008 & 0.0115 & 3.7022 & 0.0033 & 0.0259 & $>20$ \\
\hline hc & 0.0011 & 0.0143 & 3.3928 & 0.0037 & 0.0302 & 4.1174 \\
\hline $\mathrm{i}$ & 0.0018 & 0.0210 & 5.9956 & 0.0055 & 0.0473 & 8.2634 \\
\hline IC & 0.0017 & 0.0091 & 1.3545 & 0.0116 & 0.0402 & 2.5970 \\
\hline IF & 0.0009 & 0.0071 & 1.4277 & 0.0040 & 0.0274 & 2.2909 \\
\hline $\mathrm{IH}$ & 0.0004 & 0.0066 & 1.5542 & 0.0044 & 0.0265 & 2.5786 \\
\hline $\mathrm{j}$ & 0.0022 & 0.0143 & 2.6207 & 0.0049 & 0.0305 & 2.5921 \\
\hline $\mathrm{jd}$ & -0.0009 & 0.0096 & 3.3120 & -0.0033 & 0.0271 & $>20$ \\
\hline $\mathrm{jm}$ & 0.0018 & 0.0168 & 3.6576 & 0.0085 & 0.0290 & 4.1474 \\
\hline 1 & 0.0003 & 0.0111 & 4.2849 & 0.0033 & 0.0283 & $>20$ \\
\hline $\mathrm{m}$ & 0.0000 & 0.0103 & 4.6629 & 0.0019 & 0.0259 & $>20$ \\
\hline MA & 0.0001 & 0.0139 & 6.7253 & -0.0014 & 0.0304 & $>20$ \\
\hline ni & 0.0001 & 0.0128 & 5.3109 & -0.0040 & 0.0282 & $>20$ \\
\hline OI & -0.0001 & 0.0084 & 4.9719 & 0.0009 & 0.0208 & $>20$ \\
\hline $\mathrm{p}$ & 0.0002 & 0.0124 & 14.5904 & 0.0003 & 0.0308 & $>20$ \\
\hline $\mathrm{pp}$ & 0.0003 & 0.0131 & 6.7445 & 0.0031 & 0.0319 & $>20$ \\
\hline $\mathrm{rb}$ & 0.0008 & 0.0142 & 2.9974 & 0.0035 & 0.0287 & 3.4465 \\
\hline $\mathrm{RM}$ & 0.0002 & 0.0124 & 4.8491 & 0.0010 & 0.0293 & $>20$ \\
\hline $\mathrm{ru}$ & 0.0002 & 0.0153 & 3.5597 & -0.0019 & 0.0376 & $>20$ \\
\hline sn & 0.0001 & 0.0104 & 4.8154 & 0.0000 & 0.0281 & $>20$ \\
\hline SR & -0.0001 & 0.0066 & 4.3876 & 0.0011 & 0.0155 & 4.3281 \\
\hline $\mathrm{T}$ & 0.0001 & 0.0022 & 3.6540 & 0.0011 & 0.0040 & 4.2569 \\
\hline TA & -0.0002 & 0.0091 & 3.6482 & -0.0019 & 0.0220 & $>20$ \\
\hline $\mathrm{TF}$ & 0.0000 & 0.0013 & 3.0636 & 0.0009 & 0.0023 & 2.2150 \\
\hline $\mathrm{v}$ & 0.0003 & 0.0099 & 4.0383 & 0.0031 & 0.0235 & $>20$ \\
\hline $\mathrm{y}$ & 0.0001 & 0.0094 & 9.5186 & 0.0010 & 0.0216 & $>20$ \\
\hline $\mathrm{ZC}$ & 0.0005 & 0.0104 & 2.9739 & 0.0022 & 0.0307 & $>20$ \\
\hline $\mathrm{zn}$ & 0.0007 & 0.0123 & 5.6513 & 0.0009 & 0.0278 & $>20$ \\
\hline
\end{tabular}



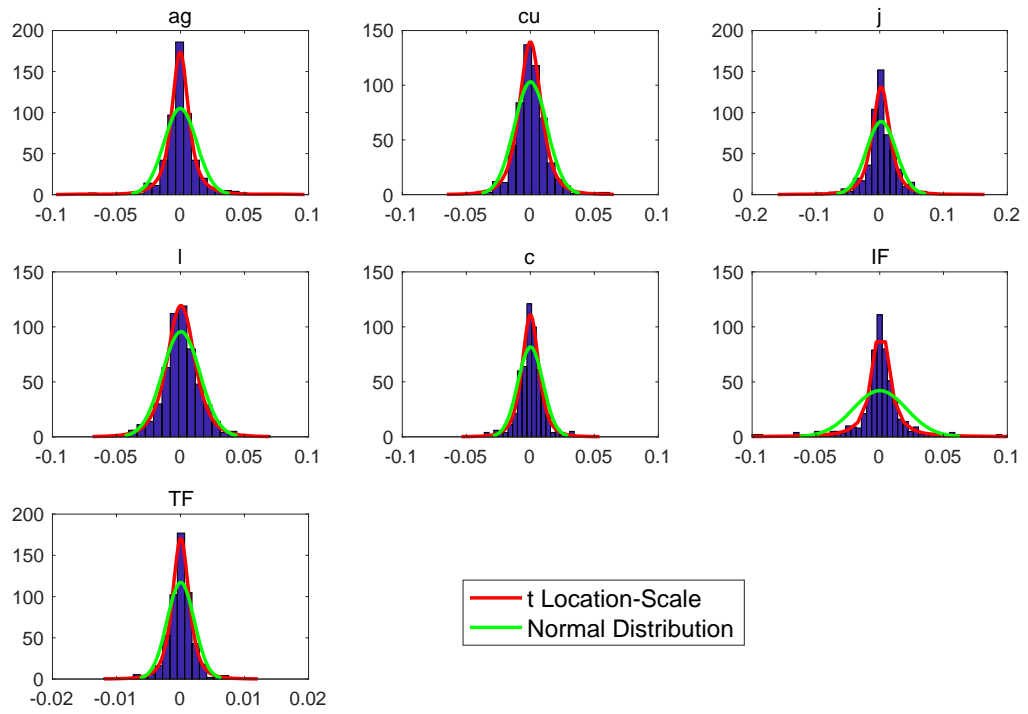

Normal Distribution

Figure 6: Normal and t Location-Scale distribution fitting plots for daily returns.

not a stylized fact for the case of futures returns and many futures products exhibit positive skewness depending on the particular trend and sub-period. Finally, similar to the stock returns, the $t$-location scale distribution provides a better fit to the log-returns of the futures contracts compared to the normal distribution.

\subsection{Principle components analysis}

Returns on stock portfolios is often explained via well-known factor models, such as the three factor model of [15]. Stock portfolio returns are decomposed by the market risk, size and value as the major risk factors. In the analysis futures products, which mostly consists of commodity futures, such risk factors are not readily available or at least do not explain the behavior of different groups of futures products well. Therefore, a natural question arises in the search for factors to explain the risk premia in futures returns. Principle components analysis can be considered as a method to understand whether there is common behavior or a factor that is driving the futures returns at different time scales. Principle component analysis help us to understand at 


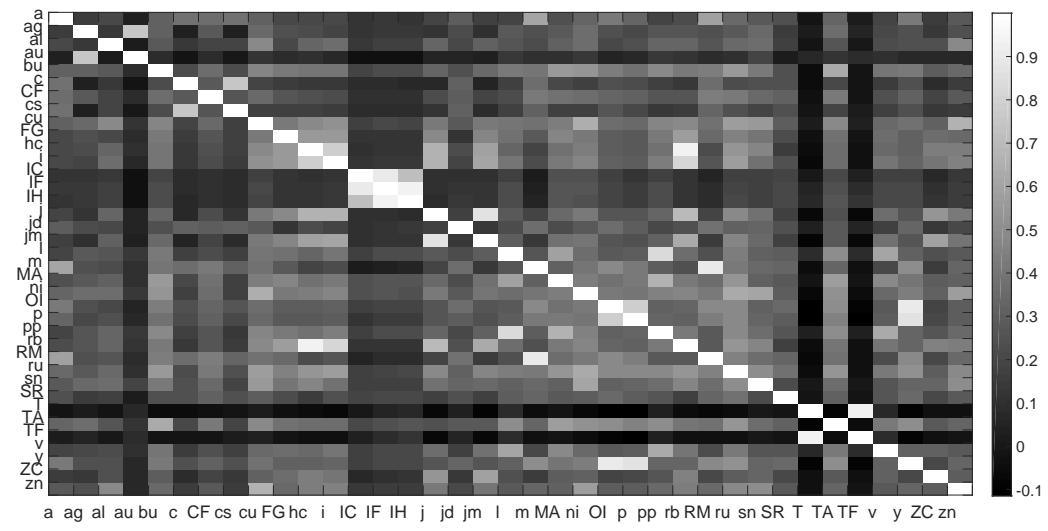

Figure 7: Correlations of close-to-close futures returns.

what time scales the common factors can be significant or how many factors would be needed for explaining the correlation structure of futures returns.

As a first step we apply the principle components analysis with the correlation matrix of futures returns at the daily time scale. The correlation matrix for the whole set of 37 futures products are given in Figure 7. Figure 7 shows that the index and bond futures do not have high correlation with the commodity futures, but financial futures are highly correlated with each other. It is also clear that futures within the same industry tend to have higher correlation. These are important observations which at least justify the diversification possibilities via investment in the commodity futures.

Principle components analysis (PCA) is one of the most commonly used statistical methods to reduce dimension of a multivariate time series (see [35]). Separation between the stock returns and commodity futures returns reveals itself in the principle components analysis. For example, if we consider the three index futures that exist in the Chinese futures markets, namely IF, IH, and IC, and apply PCA we find that the index futures are pretty much driven by a single factor. The joint scatter plot for the normalized returns (i.e. the z-scores) for the IF, IH, and IC is given in Figure 8. By applying the PCA we find that a single factor can explain about $90 \%$ of the variation of the daily returns of the index futures as given in Table 9. From a similar analysis, we find that the two bond futures, i.e. the 5- and 10-year bond futures, are also driven by a single common factor that accounts for $97 \%$ of the variation. Not 


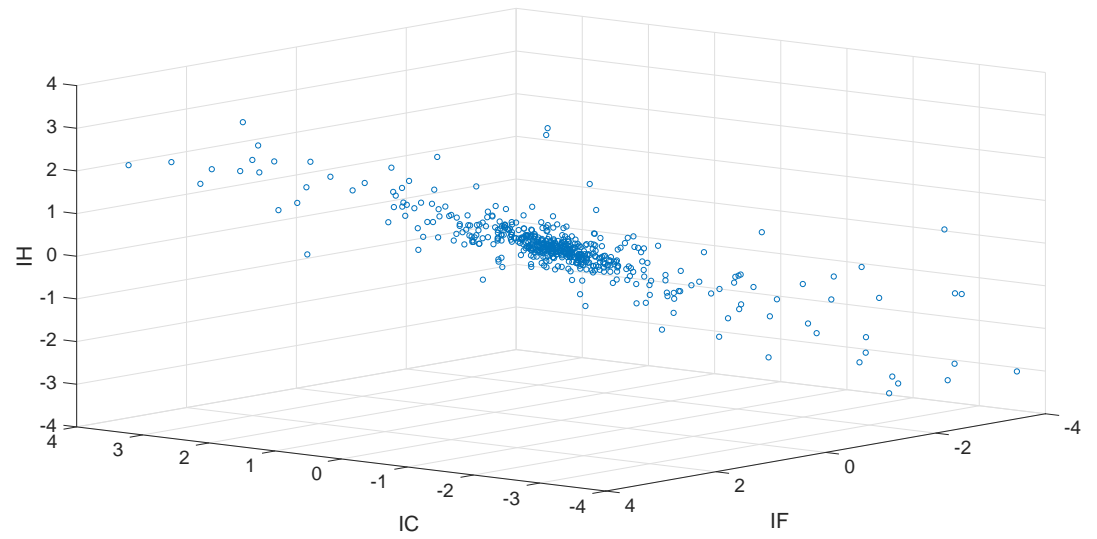

Figure 8: Scatter plot for the z-scores of the daily log-returns on index futures.

surprisingly, when we consider the index futures and bond futures together and re-apply PCA. The results given in Table 9 shows that there are mainly two factors to explain all the financial futures in the Chinese market. The first factor accounts for $89 \%$ and the second factor explains the remaining $10 \%$ of the variation in the financial futures.

When we consider the correlation matrix for the full set of 37 futures products, as given in Table 9, the first factor can only explain about $30 \%$ of the the source of variations. Moreover, even if we remove the financial futures and utilize the remaining 32 commodity futures still the first component cannot explain a high percentage of the correlation structure across these 32 products. Therefore, it is not possible to construct a single factor model that can capture the characteristics of the whole futures markets in China. To differentiate between futures products, we consider the conventional grouping of these products as financial, precious metals, industrial metals, energy and chemicals. Therefore, the detailed analysis shows that among these groups of futures, financial and precious metals can be explained in a single factor setting, whereas industrial metals can be explained with two factors (i.e. more than $80 \%$ as the threshold) and finally energy and chemicals together with the agriculture shows the existence of at least four factors in order to explain nearly $80 \%$ of the variation in these return series.

Alternatively, we also experiment with the weekly (i.e. five trading days) futures returns, however, all the experiments are not presented here for brevity. 
Table 9: Principle component analysis of daily futures returns with respect to industries

\begin{tabular}{|c|c|c|c|c|c|c|}
\hline \multirow[b]{2}{*}{ Principle Component } & \multicolumn{6}{|c|}{ Percentage of the variation explained by the first $k$-number of principle components of futures returns. } \\
\hline & Precious M. (2) & Industrial M. (8) & Energy\&Chemicals (11) & Agriculture (9) & Financial (5) & All (37) \\
\hline 1 & $89 \%$ & $63 \%$ & $43 \%$ & $37 \%$ & $88 \%$ & $31 \%$ \\
\hline 2 & $100 \%$ & $77 \%$ & $59 \%$ & $58 \%$ & $98 \%$ & $44 \%$ \\
\hline 3 & & $85 \%$ & $71 \%$ & $75 \%$ & $99 \%$ & $52 \%$ \\
\hline 4 & & $90 \%$ & $78 \%$ & $85 \%$ & $100 \%$ & $57 \%$ \\
\hline 5 & & $93 \%$ & $84 \%$ & $93 \%$ & & $62 \%$ \\
\hline 6 & & $96 \%$ & $88 \%$ & $96 \%$ & & $65 \%$ \\
\hline 7 & & $98 \%$ & $91 \%$ & $98 \%$ & & $69 \%$ \\
\hline 8 & & $100 \%$ & $94 \%$ & $99 \%$ & & $72 \%$ \\
\hline 9 & & & $97 \%$ & $100 \%$ & & $75 \%$ \\
\hline 10 & & & $99 \%$ & & & $77 \%$ \\
\hline 11 & & & $100 \%$ & & & $79 \%$ \\
\hline 18 & & & & & & $90 \%$ \\
\hline
\end{tabular}

This table illustrates the percentages explained by the first $k$-number of principle components for different industries of futures products in China. The number of products for the precious metals, industrial metals, energy and chemicals, agriculture, and financial futures are given in the paranthesis.

Overall, the use of weekly returns tend to slightly increase the proportions explained by the first few factors due to the smoothing effect at this return horizon. The use of weekly returns reduces certain short term deviations between co-moving futures products and this tends to improve the proportions explained by the first few factors. Therefore, the behavior of the dependence at different investment horizons tend to show variations to some extent. One drawback that avoids a comprehensive robustness check on the stability over time is the limited length of futures dataset in China since many of the products have recent launch dates. Nevertheless, we overcome this drawback by considering the high-frequency returns additional to the daily and weekly futures returns.

To observe the behavior of futures returns at higher frequencies we consider the 5-minute returns since at the 1-minute level the log-returns are heavily affected by the micro-structure effects such as the "bid-ask bounce". Therefore, to conduct the principle components analysis with the 5-minute log-returns we only focus on the minute level returns at the day-time trading hours since not all products have the night trading.

In Figure 9, for each trading day the principle components analysis is ap- 
plied using the intra-day correlation matrix obtained from the 5-minute level returns. The percentage of variation explained with the first few factors are displayed on the $y$-axis of the plots. For example, in the first plot of Figure 9, the first factor explains a high percentage of the intra-day correlation matrix of the index futures returns. However, there are also many spikes and the percentage explained by the first factor is quite volatile. A sudden drop in the first factor implies that during those dates index futures returns deviate from each other more significantly and are not driven by the common factor. Overall, the results are comparable with the results of principle components analysis in Table 9. For example, in Table 9 daily agricultural returns can be explained around $37 \%$ with the first factor. In Figure 9, on average the correlation matrix of the 5 minute agricultural futures returns can be explained with the first factor with a percentage ranging from $30 \%$ to $85 \%$. This implies that for the minute level futures returns, each trading day shows different degree of co-movement with respect to the common factors. Therefore, high frequency trading within a dynamic trading strategy yields very significant diversification benefits when the percentage explained with the first factor goes down. Considering the fact that minute level returns often deviate from the common factor, we can justify that dynamic CTA trading strategies offer significant diversification benefits for the Chinese stock market investors.

The difference of the dependence structure at different timescales of returns have important implications for traders in terms of diversification and exposure to common sources of risk for different products. For example, for the daily log-returns, and thus at the daily trading horizons, industrial metals have a stronger dependence on the first factor compared to the agricultural futures. Therefore, investment in different agricultural futures products have less exposure to the common risk factor that drives the industrial metals. Similarly, an investor can decide asset allocation across different products based on the common risk factors and decide how much exposure is desirable in terms of each factor. This allows us to decompose industry based futures returns and analyze potential benefits from diversification.

We conclude this subsection by verifying the correlation between the major factors for each given industry of futures contracts. Note that as a result of the PCA applied with respect to each industry, we obtain the first factor that explains the highest proportion of the correlation matrix in that industry. 

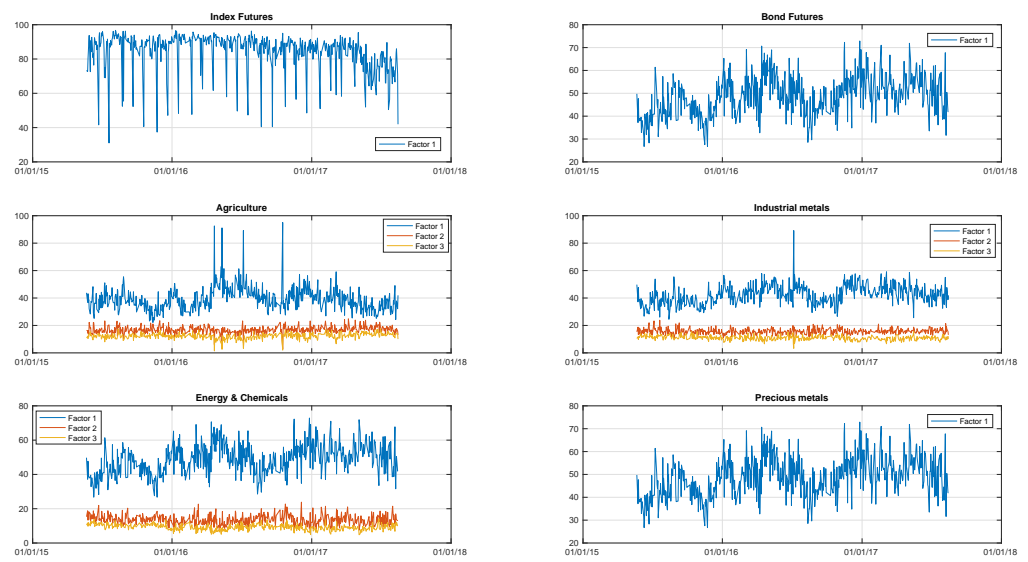

Figure 9: PCA applied using the five minute returns for the different groups of futures contracts in the Chinese market. The $y$-axis displays the proportion of variation explained by the first few principle components obtained from the intra-day correlation matrix, i.e. correlation matrix is estimated for each day using the minute level returns in the day-trading hours.

Therefore, as the final step one can check the correlations between the major factors across industries, and thus verify if these factors driving the returns in different industries are also correlated with each other or not. Note that the first factor obtained from each industry gives us a weighted average of the futures returns within that industry. In other words, it gives us an index to represent each industry. The correlation matrix is presented in Table 10 and it is observed that the major risk factor for the energy \& chemicals versus industrial metals have the highest correlations, whereas the energy \& chemicals principle component is also relatively highly correlated with the principle component of the agricultural futures. All the other factors are not highly correlated with each other, which shows that an investor can construct the principle component factors as his or her portfolio from different industries and enjoy the diversification benefits of low correlation between these factor portfolios. 
Table 10: Correlation matrix of the first factors of each industry obtained from the principle components analysis using daily futures returns.

\begin{tabular}{ccccccc}
\hline & Index & Bonds & Precious Metals & Agriculture & Industrial M. & Energy \& Chem. \\
\hline Index & 1.000 & & & & & \\
Bonds & 0.053 & 1.000 & & & & \\
Precious M. & 0.060 & 0.061 & 1.000 & & & \\
Agriculture & 0.162 & -0.075 & 0.198 & 1.000 & & \\
Industrial M. & 0.203 & -0.055 & 0.264 & 0.480 & 1.000 & 1.000 \\
Energy \& Chem. & 0.256 & -0.037 & 0.267 & 0.539 & 0.786 & \\
\hline
\end{tabular}

\subsection{Co-integration}

Principle components analysis gives us insight regarding the common drivers of correlation between different futures products. Another form of co-movement can be captured via the co-integration analysis. Co-integration is a well-studied phenomenon for the case stock markets, which often exhibit this feature. Cointegration is also closely related to the widely applied pairs trading strategy, which involves exploiting the long-run equilibrium relationship between two stocks or two portfolios. A potential problem exists in the principle components analysis if the estimated correlation matrix is not robust. For example, [2] shows that co-integration analysis is more robust than the correlation analysis on asset returns. [1] studies long-run relations among international stock market indices under different market relationship. [10] argues the existence of co-integration in the asset prices. Existing literature focus on the co-integration relationship between the Chinese markets and the international markets or between the spot markets and the futures markets Yang et al. (2004), Hua and Chen (2007), Fung and Tse (2010),Liu and An (2011). More examples of pairs trading within the framework of co-integration can be found in [2], [39], and [22]. A comprehensive study on the profitability of pairs trading in the Chinese futures markets can be found in [38].

To check the existence of co-integration we use the scaled daily log-price of futures, i.e. correcting for the the artificial roll-over returns, as explained in the data section, and test the existence of co-integration between all possible pairs of futures products in the market using the Engle-Granger co-integration test. Among the space of all possible combinations of pairs of futures, we find 
evidence of significant co-integration.

As commonly used in the pairs trading literature, the spread of two contracts is defined by the co-integration equation

$$
\ln \left(P_{t}^{i}\right)=\alpha+\gamma \ln \left(P_{t}^{j}\right)+\epsilon_{t}, \quad \epsilon_{t} \text { i.i.d. } \sim\left(0, \sigma_{\epsilon}^{2}\right)
$$

where the estimate of $\hat{\gamma}$ is used to construct the spread between the log prices of assets $i$ and $j$, which is given by

$$
X_{t}=\ln \left(P_{t}^{i}\right)-\hat{\gamma} \ln \left(P_{t}^{j}\right)
$$

Therefore, the existence of co-integration is tested by the Augmented DickeyFuller test for the spread of possible pairs of futures.

Figure 10 illustrated that the null hypothesis can be rejected in most cases at $10 \%$ significance level. In the figure, the colour from black to white represents the p-Value from low to high in the Augmented Dickey-Fuller test. In other words, the dark regions indicate the existence of co-integration for those pairs of futures contracts. Across the total 666 combinations of 37 products, there are 538 combinations with statistically significant co-integration 14. Our results confirm the findings of [38], which shows that co-integration relationship can be utilized in the framework of pairs trading strategies.

\subsection{Conditional Heteroskedasticity}

The ARCH and GARCH models introduced by [14] and [5] aimed to capture the volatility clustering effect and fat tails in the stock returns and an extensive literature followed these studies. For example, [3] claims that American stock returns can be fitted by the generalized autoregressive conditional heteroskedastic GARCH $(1,1)$ process satisfactorily. [9] illustrates that the conditional volatility of Asian daily stock data shows significant asymmetric behaviour. Additional to the volatility clustering and fat tails of returns, "leverage effect" is another stylized fact for stock returns that can be captured in asymmetric GARCH models. The leverage effect refers to the existence of negative correlation between an asset return and its changes of volatility. The

\footnotetext{
${ }^{14}$ Due to the limit of space we do not provide co-integration estimation results with details, the results are available upon request.
} 


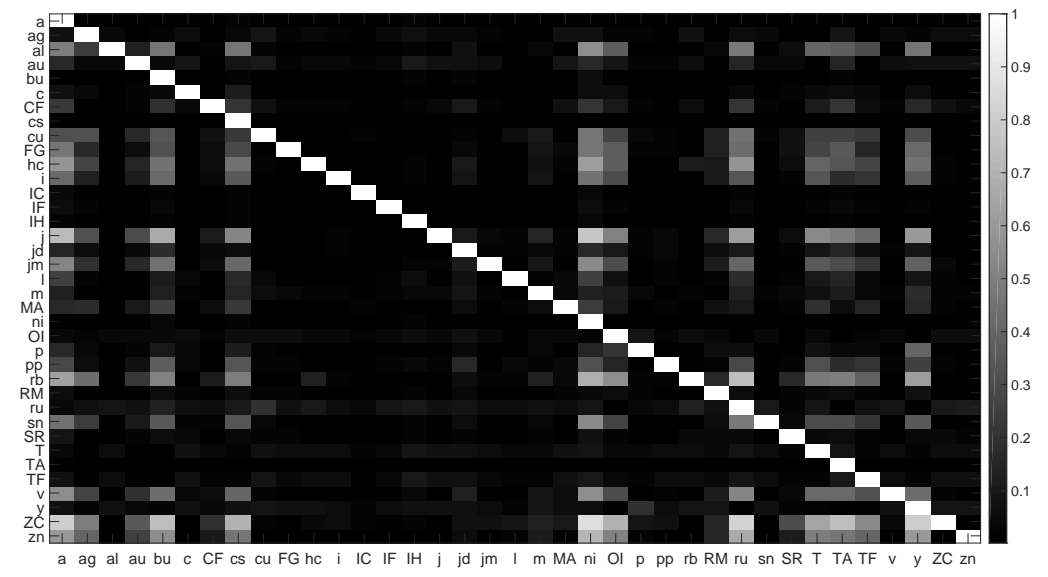

Figure 10: Augmented Dickey-Fuller test with the Cointegration Equation 8.

exponential GARCH (EGARCH) model of [29] and the GJR model of [19] are some well-known examples for detecting and capturing such behavior in asset returns. Therefore, we analyze the existence of leverage effect in futures returns by employing, the generalized autoregressive conditional heteroskedastic (GARCH) model of [14], the exponential GARCH (EGARCH) model of [29] and the GJR model of [19]. Since to the GARCH model is nested within the GJR model, the likelihood ratio test can be implemented to test the significance of parameters that captures asymmetry in the volatility equation. Moreover, EGARCH model is fitted to verify the direction of the asymmety between a futures return and its volatility.

The benchmark GARCH(1,1) model is given by

$$
\begin{aligned}
y_{t} & =\mu+\sigma_{t} z_{t}, \\
\sigma_{t}^{2} & =\kappa+\gamma \sigma_{t-1}^{2}+\alpha \epsilon_{t-1}^{2},
\end{aligned}
$$

where the innovation $z_{t}$ is following a Gaussian distribution and

$$
\kappa>0, \gamma \geq 0, \alpha \geq 0, \gamma+\alpha<1
$$

need to be satisfied for stationarity and positivity of the volatility. To extent the traditional GARCH model, the logarithm of the conditional volatility process is included in the EGARCH model. With the additional logarithm term, the EGARCH model is capable of capturing the asymmetry in the volatility 
clustering. The volatility in the $\operatorname{EGARCH}(1,1)$ model is formulated as:

$$
\log \sigma_{t}^{2}=\kappa_{e}+\gamma_{e} \log \sigma_{t-1}^{2}+\alpha_{e}\left[\frac{\left|\epsilon_{t-1}\right|}{\sigma_{t-1}}-\mathbb{E}\left[\frac{\left|\epsilon_{t-1}\right|}{\sigma_{t-1}}\right]\right]+\xi_{e}\left(\frac{\epsilon_{t-1}}{\sigma_{t-1}}\right) .
$$

For Gaussian distribution,

$$
\mathbb{E}\left[\frac{\left|\epsilon_{t-1}\right|}{\sigma_{t-1}}\right]=\mathbb{E}\left[\left|z_{t-1}\right|\right]=\sqrt{\frac{2}{\pi}}
$$

The GJR model provides an alternative formulation for capturing the asymmetric volatility clustering in terms of the threshold between positive and negative lagged innovations. In the GJR $(1,1)$ model, the volatility is given by

$$
\sigma_{t}^{2}=\kappa_{g}+\gamma_{g} \sigma_{t-1}^{2}+\alpha_{g} \epsilon_{t-1}^{2}+\xi_{g} I\left[\epsilon_{t-1}<0\right] \epsilon_{t-1}^{2},
$$

where the indicator function $I\left[\epsilon_{t-1}<0\right]=1$ for $\epsilon_{t-1}<0$, otherwise, $I\left[\epsilon_{t-1}<\right.$ $0]=0$. Additionally, the GJR $(1,1)$ model has the following constraints similar to the $\operatorname{GARCH}(1,1)$ model:

$$
\kappa_{g}>0, \gamma_{g} \geq 0, \alpha_{g} \geq 0, \alpha_{g}+\xi_{g} \geq 0, \gamma_{g}+\alpha_{g}+\frac{1}{2} \xi_{g}<1 .
$$

Table 11 displays the estimation results in fitting the conditional variance models with respect to various assumptions. The results are in agreement with the past studies for the equity market, the futures data provides strong evidence of time-varying volatility Koutmos (1998), Lee et al. (2001). The table illustrates that the traditional $\operatorname{GARCH}(1,1)$ model is rejected in favor of the GJR(1,1) model in 14 out of 37 products with respect to the log-likelihood test at the 0.05 significance level, while the restricted model can not be rejected for the other products. Meanwhile, the leverage coefficient estimates, i.e. $x i_{g}$ in Table 11, provide evidence in favor of the "leverage effect" for 17 out of 37 products by the t-test. Note that in most of the products we have a negative value for $x i_{g}$, which shows that positive shocks are correlated with a higher volatility in the futures products. This is opposite to what is often observed in the stock markets, where negative returns are correlated with higher volatility. Furthermore, the mixed signs of the leverage coefficient in the GJR $(1,1)$ model demonstrate that in futures markets during bullish periods for a particular product positive returns is likely to be correlated with the volatility, whereas during bearish times negative returns might be correlated with the higher 
volatility, which is consistent with the findings of [8]. Additionally, the opposite sign of the leverage coefficient in the $\operatorname{EGARCH}(1,1)$ model confirms that both negative and positive leverage effect can be observed depending on the specific futures products.

\section{Conclusion}

In this article we introduce and discuss a variety of stylized facts for the case of Chinese futures markets utilizing the daily, weekly and high-frequency (minute level) returns for the comprehensive set of 37 products in the market. It should also be mentioned that our data processing methodology follows the hedge fund industry practice of utilizing the most active contract for each trading day instead of applying a uniform contract roll-over methodology across different products. The main statistical and empirical features of the Chinese futures market can be summarized as follows.

- Serial correlation: For the daily returns serial correlation in most of the futures returns are weak. However, the major exception is the case of index futures, which is likely to be due to the existing restrictions on the number of long or short positions allowed per account. For the minute level futures returns, serial correlation is significant for all the products and micro-structure effects come into play as in the case of stock returns.

- Volatility clustering: Financial futures, including the index and bond futures, show the strongest volatility clustering effect which reveals itself as high dependence or serial correlation with the previous few days' squared returns. For the commodity futures volatility clustering effect seems to be weaker and more than half of the products do not show significant volatility clustering effect.

- Unit root and stationarity: Employing the unit root tests with different specifications, we find that only for a few cases the unit root can be rejected in the log-prices of futures returns, which shows that the random walk hypothesis can be rejected for these products, whereas for most of the products such direct conclusion is not possible. 
Table 11: Summary of the estimation results for the conditional variance models, namely EGARCH(1,1) and GJR(1,1) models.

\begin{tabular}{|c|c|c|c|c|c|c|c|c|c|}
\hline \multirow{2}{*}{ Products } & \multicolumn{4}{|c|}{$\operatorname{EGARCH}(1,1)$} & \multicolumn{5}{|c|}{$\operatorname{GJR}(1,1)$} \\
\hline & $\kappa_{e}$ & $\gamma_{e}$ & $\alpha_{e}$ & $\xi_{e}$ & $\kappa_{g}$ & $\gamma_{g}$ & $\alpha_{g}$ & $\xi_{g}$ & $\mathrm{P}$-value \\
\hline $\mathrm{a}$ & -0.2548 & $0.9709^{*}$ & $0.1073^{*}$ & 0.0178 & 0.0000 & $0.9214^{*}$ & $0.0598^{*}$ & $-0.0335^{*}$ & 0.1656 \\
\hline ag & $-14.2286^{*}$ & $-0.6303^{*}$ & $0.0873^{*}$ & $0.0503^{*}$ & $0.0000^{*}$ & $0.7182^{*}$ & $0.1037^{*}$ & $-0.0881 *$ & 0.0214 \\
\hline al & $-0.5287^{*}$ & $0.9401^{*}$ & $0.2056^{*}$ & $0.0681^{*}$ & $0.0000^{*}$ & $0.8636^{*}$ & $0.1446^{*}$ & $-0.0915^{*}$ & 0.0119 \\
\hline au & $-0.8840^{*}$ & $0.9062 *$ & $0.1533^{*}$ & $0.0613^{*}$ & $0.0000^{*}$ & $0.8318^{*}$ & $0.1278^{*}$ & $-0.1278^{*}$ & 0.2124 \\
\hline bu & -0.6623 & $0.9150 *$ & 0.0187 & $0.0567 *$ & 0.0004 & 0.1046 & 0.0051 & - & 1.0000 \\
\hline $\mathrm{c}$ & -0.5264 & $0.9425^{*}$ & $0.0874^{*}$ & $0.0498^{*}$ & 0.0000 & $0.9000^{*}$ & $0.0500^{*}$ & - & 1.0000 \\
\hline $\mathrm{CF}$ & $-0.2040^{*}$ & $0.9770^{*}$ & 0.0145 & $0.1645^{*}$ & $0.0000 *$ & $0.9387^{*}$ & $0.0956^{*}$ & $-0.0956^{*}$ & 0.0000 \\
\hline cs & -0.2956 & $0.9663^{*}$ & $0.1140^{*}$ & 0.0124 & 0.0000 & $0.9264^{*}$ & $0.0585^{*}$ & -0.0228 & 0.3672 \\
\hline $\mathrm{cu}$ & $-0.7004^{*}$ & $0.9192^{*}$ & $0.2379^{*}$ & $0.0414^{*}$ & $0.0000 *$ & 0.8031 * & $0.1166^{*}$ & -0.0261 & 0.4708 \\
\hline $\mathrm{FG}$ & $-0.0285^{*}$ & $0.9972^{*}$ & $-0.0385^{*}$ & $0.1089^{*}$ & $0.0000^{*}$ & $0.9000^{*}$ & $0.0500^{*}$ & - & 1.0000 \\
\hline hc & $-0.1120^{*}$ & $0.9851^{*}$ & $0.0865^{*}$ & $0.0460^{*}$ & 0.0000 & $0.9530^{*}$ & $0.0730^{*}$ & $-0.0624^{*}$ & 0.0006 \\
\hline $\mathrm{i}$ & -0.0273 & $0.9962^{*}$ & 0.0210 & $0.0572^{*}$ & 0.0000 & $0.9570^{*}$ & $0.0686^{*}$ & $-0.0588^{*}$ & 0.0046 \\
\hline IC & $-0.0410^{*}$ & $0.9953^{*}$ & $0.0365^{*}$ & $-0.1072^{*}$ & $0.0000^{*}$ & $0.9513^{*}$ & $0.0672^{*}$ & - & 0.0005 \\
\hline IF & $-0.0578^{*}$ & $0.9928^{*}$ & $0.0821^{*}$ & $-0.0706^{*}$ & $0.0000^{*}$ & $0.9497^{*}$ & 0.0008 & $0.0702 *$ & 0.0035 \\
\hline $\mathrm{IH}$ & $-0.0702^{*}$ & $0.9908^{*}$ & $0.1212^{*}$ & $-0.0496^{*}$ & 0.0000 & $0.9337^{*}$ & $0.0379^{*}$ & 0.0344 & 0.1896 \\
\hline $\mathrm{j}$ & $-0.1037^{*}$ & $0.9858^{*}$ & $0.0535^{*}$ & $0.0654^{*}$ & $0.0000^{*}$ & $0.9484^{*}$ & $0.0934^{*}$ & $-0.0934^{*}$ & 0.0000 \\
\hline jd & $-14.1888^{*}$ & $-0.6620^{*}$ & -0.0740 & -0.0474 & $0.0000 *$ & $0.9000 *$ & $0.0500^{*}$ & - & 1.0000 \\
\hline $\mathrm{jm}$ & $-0.0710^{*}$ & $0.9904^{*}$ & $0.0541^{*}$ & $0.0803^{*}$ & 0.0000 & $0.9522^{*}$ & $0.0881^{*}$ & $-0.0881 *$ & 0.0000 \\
\hline 1 & -2.9312 & $0.6532^{*}$ & -0.0035 & $-0.0885^{*}$ & 0.0002 & 0.2106 & 0.0897 & - & 0.0687 \\
\hline $\mathrm{m}$ & $-0.4119^{*}$ & $0.9526^{*}$ & $0.0952 *$ & $0.0784^{*}$ & $0.0000 *$ & $0.9003^{*}$ & $0.1042^{*}$ & $-0.1042^{*}$ & 0.0008 \\
\hline MA & -1.5226 & $0.8142^{*}$ & $0.1818^{*}$ & -0.0199 & 0.0001 & $0.7355^{*}$ & 0.0753 & 0.0087 & 0.8814 \\
\hline ni & -1.9247 & $0.7670^{*}$ & $0.1468^{*}$ & 0.0102 & 0.0001 & $0.6421^{*}$ & 0.0998 & -0.0345 & 0.5134 \\
\hline OI & $-15.7914^{*}$ & $-0.7362^{*}$ & -0.0878 & -0.0221 & 0.0000 & $0.9614^{*}$ & $0.0466^{*}$ & $-0.0369^{*}$ & 0.1141 \\
\hline $\mathrm{p}$ & -0.1688 & $0.9804^{*}$ & 0.0503 & 0.0010 & 0.0000 & $0.9000^{*}$ & 0.0500 & - & 1.0000 \\
\hline pp & -0.4796 & $0.9421^{*}$ & 0.0757 & 0.0077 & 0.0000 & $0.9039^{*}$ & 0.0428 & -0.0132 & 0.5903 \\
\hline $\mathrm{rb}$ & $-0.0808^{*}$ & $0.9894^{*}$ & 0.0220 & $0.0663^{*}$ & 0.0000 & $0.9330^{*}$ & $0.0945^{*}$ & $-0.0660^{*}$ & 0.0007 \\
\hline $\mathrm{RM}$ & $-0.4667^{*}$ & $0.9435^{*}$ & $0.1393^{*}$ & 0.0288 & $0.0000^{*}$ & $0.8886^{*}$ & $0.0870^{*}$ & -0.0548 & 0.1360 \\
\hline $\mathrm{ru}$ & $-0.0235^{*}$ & $0.9974^{*}$ & $-0.0367^{*}$ & $0.0662^{*}$ & 0.0000 & $0.9847^{*}$ & $0.0306^{*}$ & $-0.0306^{*}$ & 0.0001 \\
\hline sn & $-0.6272^{*}$ & $0.9270^{*}$ & $0.1680^{*}$ & 0.0292 & $0.0000^{*}$ & $0.8574^{*}$ & $0.1029^{*}$ & -0.0547 & 0.0769 \\
\hline SR & -0.3468 & $0.9628^{*}$ & $0.0923^{*}$ & 0.0015 & 0.0000 & $0.9000^{*}$ & $0.0500^{*}$ & - & 1.0000 \\
\hline $\mathrm{T}$ & $-0.3422^{*}$ & $0.9706^{*}$ & $0.1821^{*}$ & $-0.0720^{*}$ & 0.0000 & $0.8892 *$ & $0.0471^{*}$ & $0.0775^{*}$ & 0.0002 \\
\hline $\mathrm{TA}$ & $-4.4251^{*}$ & $0.4927^{*}$ & $0.3802 *$ & 0.0163 & $0.0001 *$ & 0.1492 & $0.2469^{*}$ & 0.0073 & 0.9467 \\
\hline $\mathrm{TF}$ & $-0.2516^{*}$ & $0.9799^{*}$ & $0.1356^{*}$ & $-0.1074^{*}$ & 0.0000 & $0.7037^{*}$ & $0.1491^{*}$ & $0.2160^{*}$ & 1.0000 \\
\hline $\mathrm{v}$ & $-0.3888^{*}$ & $0.9541^{*}$ & $0.1784^{*}$ & 0.0064 & $0.0000^{*}$ & $0.8762 *$ & $0.0898 *$ & -0.0042 & 0.8935 \\
\hline $\mathrm{y}$ & -0.6036 & $0.9335^{*}$ & $0.1270^{*}$ & 0.0023 & 0.0000 & $0.9000^{*}$ & 0.0500 & - & 1.0000 \\
\hline $\mathrm{ZC}$ & $-0.2588^{*}$ & $0.9684^{*}$ & $0.0818^{*}$ & $0.0460^{*}$ & 0.0000 & $0.9397^{*}$ & $0.0749^{*}$ & $-0.0703^{*}$ & 0.0051 \\
\hline $\mathrm{zn}$ & $-0.5910^{*}$ & $0.9290 *$ & $0.1479^{*}$ & -0.0504 & $0.0000^{*}$ & $0.9000^{*}$ & $0.0500 *$ & - & 1.0000 \\
\hline
\end{tabular}

P-value ${ }^{l}$ represents the p-value for the likelihood ratio test for the GJR model and the GARCH model.

- represents that the leverage term is close to zero (reduced) in the estimation by Econometrics toolbox in MATLAB.

* represents that the coefficient is statistically significant at the 0.05 level. 
- Distributional properties: The non-normality of futures returns is in line with the stylized facts of stock returns. Furthermore, we show that the $t$-location scale is a more suitable candidate for modeling the futures returns. Second, aggregational Gaussianity property can be observed in the futures returns similar to the stock markets. Third, negative skewness, which often observed in stock return distributions, is not the case for most of the futures returns and the sign of skewness seem to depend on the bullish or bearish periods of products.

- Principle components: Principle components analysis (PCA) is employed to decompose the correlation between futures products. The percentage of variation explained by the first few factors is highest in the industrial metals sector of futures, in other words, within this group of futures contracts the first common factor can explain most of the correlations among futures contracts. Similarly, financial futures show high dependence and co-movement with the first factor explaining a high ratio of the correlation matrix. PCA applied in the high frequency returns shows that intra-day co-movement of futures returns and the correlation matrix can be explained with the first few factors as well. For specific industry groups of futures products, a high explanatory power for the first component indicates there is less diversification benefits from investment within that group of futures.

- Co-integration: There are many pairs of futures products that are cointegrated in the Chinese futures markets. Therefore, trading strategies, such as pairs trading strategy, can be justified within this framework.

- Conditional heteroskedasticity: Additional to the existence of volatility clustering, there is asymmetry in the correlation between a futures return and its volatility. Different from stock returns, positive leverage effect is more common in the futures returns. In other words, the direction of asymmetry is not uniform across different products, which is likely to depend on the bullish or bearish investment periods as well.

Overall, in this article we provide an analysis of the fundamental statistical and empirical features of the futures returns in China. It should be noted that the stylized facts in stock markets cannot be easily generalized to the case of 
futures markets. The empirical properties of futures returns documented in this study can be considered as an input for various models of investment or risk management.

\section{References}

[1] Alexakis, C., Long-run relations among equity indices under different market conditions: Implications on the implementation of statistical arbitrage strategies, Journal of International Financial Markets, Institutions and Money, 20(4), (2010), 389 - 403.

[2] Alexander, C. and Dimitriu, A., Indexing and statistical arbitrage, Journal of Portfolio Management, 31(2), (2005), 50 - 63.

[3] Akgiray, V., Conditional heteroscedasticity in time series of stock returns: Evidence and forecasts, Journal of business, 62(1), (1989), 55 - 80.

[4] Baillie, R. T. and Myers, R. J., Bivariate GARCH estimation of the optimal commodity futures hedge, Journal of Applied Econometrics, 6(2), (1991), $109-124$.

[5] Bollerslev, T., Generalized Autoregressive Conditional Heteroskedasticity, Journal of Econometrics, 31(3), (1986), 307 - 327.

[6] Bollerslev, T., A conditionally heteroskedastic time series model for speculative prices and rates of return, The review of economics and statistics, 69(3), (1987), $542-547$.

[7] Bouchaud, J.P. and Potters, M., More stylized facts of financial markets: leverage effect and downside correlations, Physica A, 299, (2001), 60 - 70.

[8] Chan, K.C., Fung, H. G. and Leung, W.K., Daily volatility behavior in Chinese futures markets, Journal of International Financial Markets, 14, (2004), $491-505$.

[9] Chiang, T. C. and Doong, S. C., Empirical analysis of stock returns and volatility: Evidence from seven Asian stock markets based on TAR- 
GARCH model, Review of Quantitative Finance and Accounting, 17(3), (2001), $301-318$.

[10] Chiu, M. and Wong, H., Mean-variance portfolio selection of cointegration assets, Journal of Economic Dynamics \& Control, 35, (2001), 1369 - 1385.

[11] Cont, R., Empirical properties of asset returns: stylized facts and statistical issues, Quantitative Finance, 1, (2001), 223 - 236.

[12] Daal, E., Naka, A. and Yu, J. S., Volatility clustering, leverage effects, and jump dynamics in the US and emerging Asian equity markets, Journal of Banking and Finance, 31(9), (2007), 2751 - 2769.

[13] Delatte, A. L. and Lopez, C., Commodity and Equity Markets: Some Stylized Facts from a Copula Approach, Journal of Banking \& Finance, 37(12), (2013), 5346 - 5356 .

[14] Engle, R. F., Autoregressive Conditional Heteroskedasticity with Estimates of the Variance of United Kingdom Inflation, Econometrica, 50, (1982), 987 - 1007.

[15] Fama, E.F. and French, K.R., Common Risk Factors in the Returns on Stock and Bonds, Journal of Financial Economics, 33(1), (1993), 3 - 56.

[16] Fama, E.F., Market efficiency, long-term returns, and behavioral finance, Journal of Financial Economics, 49, (1998), 283306.

[17] Friedmann, R. and Kohle, W.G.S., Volatility Clustering and Nontrading Days in Chinese Stock Markets, Journal of Economics and Business, 54(2), (2002), 193 - 217.

[18] Fung, H. G. and Tse, Y., The information flow and market efficiency between the US and Chinese aluminum and copper futures markets, Journal of Futures Markets, 30(12), 1192 - 1209.

[19] Glosten, L. R., Jagannathan, R. and Runkle, D. E., On the Relation between the Expected Value and the Volatility of the Nominal Excess Return on Stocks, The Journal of Finance, 48(5), 1779 - 1801. 
[20] S.Hogan, R. Jarrow, M. Teo, and Warachka, M., Testing Market Efficiency using Statistical Arbitrage with Applications to Momentum and Value Trading Strategies, Journal of Financial Economics, 73, (2004), 525 565.

[21] Hua, R. and Chen, B., International linkages of the Chinese futures markets, Applied Financial Economics, 17, (2007), 12751287.

[22] Goncu, A., Akyildirim, E., Statistical Arbitrage with Pairs Trading", International Review of Finance, 16(2), (2016), 307 - 319.

[23] Jacobsen, B. and Dannenburg, D., Volatility clustering in monthly stock returns, Journal of Empirical Finance, 10(4), (2003), 479 - 503.

[24] Koutmos, G., Asymmetries in the conditional mean and the conditional variance: Evidence from nine stock markets, Journal of Economics and Business, 50(3), (1998), 277 - 290.

[25] Lee, C. F., Chen, G. M. and Rui, O. N., Stock returns and volatility on China's stock markets, Journal of Financial Research, 24(4), (2001), 523 -543 .

[26] Liu, Q. and An, Y., Information transmission in informationally linked markets: Evidence from US and Chinese commodity futures markets, Journal of International Money and Finance, 30(5), (2001), 778 - 795.

[27] Marshall, B.R., Cahan, R.H. and Cahan, J.M., Can commodity futures be profitably traded with quantitative market timing strategies?, Journal of Banking \& Finance, 32(9), (2008), 1810 - 1819.

[28] Miffre, J. and Rallis, G., Momentum Strategies in Commodity Futures Markets, Journal of Banking \& Finance, 34, (2007), 2530 - 2548.

[29] Nelson, D. B., Stationarity and persistence in the GARCH $(1,1)$ model, Econometric Theory, 6, (1990), 318 - 334.

[30] Nelson, C. R. and Plosser, C. R., Trends and random walks in macroeconomic time series: some evidence and implications, Journal of monetary economics, 10(2), (1982), 139 - 162. 
[31] Pagan, A., The econometrics of financial markets, Journal of Empirical Finance, 3, (1996), 15 - 102.

[32] Peiro, A., The distribution of stock returns: international evidence, $A p$ plied Financial Economics, 4(6), 431 - 439.

[33] Perron, P., The great crash, the oil price shock, and the unit root hypothesis, Econometrica: Journal of the Econometric Society, (1989), 1361 1401 .

[34] Shen, Q., Szakmary, A. and Sharma, S., An Examination of Momentum Strategies in Commodity Futures Markets, Journal of Futures Markets, 27(3), (2007), 227 - 256.

[35] Tsay, R.S., Analysis of Financial Time Series, (2005), John Wiley \& Sons.

[36] Wang, C. and Yu, M., Trading activity and price reversals in futures markets, Journal of Banking \& Finance, 28(6), (2004), 1337 - 1361.

[37] Yang, J., Yang, Z. and Zhou, Y., Intraday price discovery and volatility transmission in stock index and stock index futures markets: Evidence from China, Journal of Futures Markets, 32(2), (2004), 99 - 121.

[38] Yang, Y., Goncu, A. and Pantelous, A., Pairs trading with commodity futures: evidence from the Chinese market, China Finance Review International, $7(3)$, (2017), $274-294$.

[39] Zeng, Z. and Lee, C., Pairs trading: optimal thresholds and profitability, Quantitative Finance, 14(11), (2014), 1881 - 1893. 